\title{
Effect of process variables on the structure, residual stress, and hardness of sputtered nanocrystalline nickel films
}

\author{
R. Mitra \\ Defence Metallurgical Research Laboratory, Kanchanbagh, Hyderabad 500 058, India \\ R.A. Hoffman and A. Madan \\ Advanced Coating Technology Group, Northwestern University, Evanston, Illinois 60208 \\ J.R. Weertman \\ Department of Materials Science and Engineering, Northwestern University, Evanston, Illinois 60208
}

(Received 8 June 2000; accepted 17 January 2001)

\begin{abstract}
Nanocrystalline nickel films of about $0.1 \mu \mathrm{m}$ thickness grown by sputtering with and without substrate bias possessed average grain sizes of 9-25 nm. Variation in substrate bias at room and liquid nitrogen temperature of deposition strongly affected grain structure and size distribution. Qualitative studies of film surfaces showed variation in roughness and porosity level with substrate bias and film thickness (maximum of $8 \mu \mathrm{m})$. The films had tensile residual stress, which varied with deposition conditions. The hardness values were much higher than those of coarse-grained nickel but decreased with an increase in the film thickness because of grain growth.
\end{abstract}

\section{INTRODUCTION}

Nanocrystalline metals have generated a great deal of interest in recent years because they demonstrate impressive mechanical behavior characterized by very high strengths. ${ }^{1-3}$ Strengthening is induced by the restricted deformation of nanoscale grains, which inhibit dislocation activity, and also by the presence of a large volume fraction of grain boundaries. Studies ${ }^{2-4}$ on bulk nickel processed by inert gas condensations ${ }^{5}$ (IGC) have shown very high hardness and yield strengths, which are as much as $25 \%$ of the theoretical shear strength of the metal and half that of dislocation-free single-crystal whiskers. The compaction of nanocrystalline powders produced by methods like IGC has often led to grain growth $^{6}$ (in the case of warm compaction) and flaws such as closed porosities, heterogeneities in grain size distribution, ${ }^{7}$ etc. These consequences of the compaction process could adversely affect the mechanical properties. Hence, it is necessary to experiment with alternative methods of synthesis.

Other methods of synthesis include electrodeposition, ${ }^{8-10}$ ball milling, ${ }^{11}$ and physical vapor deposition processes such as magnetron sputtering ${ }^{12-16}$ and electron beam evaporation. ${ }^{17-20}$ Nanocrystalline Ni specimens processed by electrodeposition ${ }^{8,9}$ have shown very high hardness and strength values. However, samples prepared by electrodeposition can have impurities from the plating process. ${ }^{10}$ While ball milling results in contamination from different sources, magnetron sputtering leads to high purity powders. Both pure metallic and alloy powders have been generated by magnetron sputtering of suitable targets. ${ }^{12}$ It has been found that the size of the powder particles produced by magnetron sputtering depends on the Ar pressure; a pressure of around 150 mtorr yielded powders with nanocrystalline particles. ${ }^{13}$ The goal of these experiments was to generate nanocrystalline powders and not film or bulk samples. Nanocrystalline metallic films have been processed using both magnetron sputtering ${ }^{14-16}$ and electron beam evaporation. ${ }^{17-20}$ At a given homologous temperature, $T_{\mathrm{s}} / \mathrm{T}_{\mathrm{m}}$ ( $T_{\mathrm{s}}=$ substrate temperature and $T_{\mathrm{m}}=$ melting point of target material), grain size in the sputtered films depends on a number of factors, such as substrate-to-target distance, power to target, deposition rate, bias, etc. Magnetron sputtering has been used to deposit nanocrystalline films of $\mathrm{Fe},{ }^{14} \mathrm{Cr},{ }^{15}$ and $\mathrm{Ni}-\mathrm{Cr}$ alloy films. ${ }^{16}$ Roomtemperature sputter-deposited 1.0-1.2- $\mu$ m-thick Fe films ${ }^{14}$ possess an average grain size of $11 \mathrm{~nm}$ with argon sputtering pressure of 12 mtorr. The $\mathrm{Cr}$ films ${ }^{15}$ deposited at room temperature using argon pressures between 1.1 and $7.5 \mathrm{~m}$ torr possess grain sizes in the range of $16-20 \mathrm{~nm}$.

Nickel films like other metallic thin films have been studied in detail ${ }^{16,18-23}$ with the goal of applications such as protective layers ${ }^{24}$ or contact layers in microelectronic circuitry. ${ }^{25}$ The grain size and morphology of metallic films strongly affect their properties such as hardness ${ }^{24}$ in protective layers and conductivity in electrical devices. ${ }^{26}$ The mechanical properties of the metallic film depend on the grain structure and size distribution, density, and internal residual stress, and this dependence makes it important to understand processing- 
microstructure-property relationships in metallic films. The deposition conditions such as $T_{\mathrm{s}} / T_{\mathrm{m}}$ ratio, substrate bias, and sputtering pressure as well as the the grain structure determine the magnitude and sign of the internal residual stress in thin films. ${ }^{15,27-29}$ Grovenor et al. ${ }^{20}$ have reported that the grain structures in thin $(100 \mathrm{~nm}$ in thickness) and thick (9-14 $\mu \mathrm{m}$ in thickness) Ni films processed by electron beam evaporation and deposited at the rate of 1 and $16 \mathrm{~nm} / \mathrm{s}$, respectively, show strong dependence on $T_{\mathrm{s}} / T_{\mathrm{m}}$ and film thickness. Films deposited at substrate temperatures of less than $0.15 T_{\mathrm{m}}$ have homogeneous, equiaxed grain structures in the size range of 5-20 nm. As the substrate temperature increases, the grain boundary mobility rises, leading to an increase in the grain size. Inhomogeneous grain size distribution was observed in the films deposited at $0.3 T_{\mathrm{m}}$. At higher temperatures, a columnar grain structure was observed. In contrast to the observations of Grovenor et al. ${ }^{20}$ studies by Movchan and Demchishin ${ }^{30}$ on thick coatings (250-2000 $\mu \mathrm{m}$ ) of $\mathrm{Ni}, \mathrm{Ti}, \mathrm{W}, \mathrm{Al}_{2} \mathrm{O}_{3}$, and $\mathrm{ZrO}_{2}$ deposited by evaporation on substrates at different temperatures at higher rates of $17-34 \mathrm{~nm} / \mathrm{s}$ have shown that columnar structure forms at lower temperatures, and equiaxed grain structure was observed at higher temperatures. $T_{\mathrm{s}} /$ $T_{\mathrm{m}}$ has been divided into three zones: (i) zone $1, T_{\mathrm{s}} / T_{\mathrm{m}}<$ 0.25 to 0.3 , consisting of tapered crystallites with domed tops which increase in width with temperature; (ii) zone $2,0.25$ to $0.3<T_{\mathrm{s}} / T_{\mathrm{m}}<0.45$, showing columnar grains with smooth matte surface; and (iii) zone $3, T_{\mathrm{s}} / T_{\mathrm{m}}>0.45$, characterized by equiaxed grain and glossy surface. Thornton zone diagrams ${ }^{31}$ are based on studies on coatings of $\mathrm{Mo}, \mathrm{Cr}, \mathrm{Ti}, \mathrm{Fe}, \mathrm{Cu}$, and $\mathrm{Al}$ alloy up to $25 \mu \mathrm{m}$ thickness on glass and metallic substrates, deposited by sputtering of post or hollow cathodes at rates in the range of $1.7-3.3 \mathrm{~nm} / \mathrm{s}$, using varying substrate temperatures, argon pressures, and ion bombardments. Thornton has shown that (i) at $T_{\mathrm{s}} / T_{\mathrm{m}}<0.1$, due to little adatom mobility, growth is in the direction of coating flux with formation of tapered crystallites and intergrain boundaries full of voids; (ii) at $0.1<T_{\mathrm{s}} / T_{\mathrm{m}}<0.3$, self-diffusion becomes appreciable, and microstructure contains a dense array of fibrous grains with fewer intergranular voids due to occurrence of sintering type coalescence; (iii) at $0.3<T_{\mathrm{s}} / T_{\mathrm{m}}<0.5$, columnar grains form extending across the thickness of the film, while at higher temperatures, the surfaces are faceted. The Ni films processed by direct current (dc) triode sputter deposition by Dahlgren et $a .^{21}$ between the substrate temperatures of $-150{ }^{\circ} \mathrm{C}$ and $200{ }^{\circ} \mathrm{C}$ show a mixture of columnar and equiaxed grains. The columnar morphology could be completely altered to an equiaxed grain structure by application of a substrate bias in the case of $1-25 \mu \mathrm{m}$ thick films. ${ }^{22,23}$ Dahlgren et al. ${ }^{21}$ also observed a yield strength of 1.0 GPa in tension tests of $\mathrm{Ni}$ specimens with $50-\mathrm{nm}$ grain size and with a microstructure containing a mixture of columnar and equiaxed grains. This work indeed showed the potential of sputter deposition as a process to make bulk nanocrystalline or fine-grained specimens. Average grain sizes were used to correlate with yield strengths, but a need for grain size distribution was strongly emphasized.

In the present study, "thin" and "thick" $(0.1-8 \mu \mathrm{m}$ in thickness) films of nanocrystalline $\mathrm{Ni}$ were processed by dc magnetron sputtering, with the substrate at room or liquid nitrogen temperature. The effects of different processing parameters on grain size distribution and morphology, surface porosity and topography, internal residual stress, and hardness are reported in this paper.

\section{EXPERIMENTAL PROCEDURE}

Ni films were grown on $\mathrm{Si}(100)$ wafers, M2 ${ }^{\text {Wix }}$ alloy steel, $\mathrm{NaCl}$, or $\mathrm{Cu}$ grids with holey carbon films (supplied by Ted Pella, Inc., Redding, CA) as substrates, using a dc magnetron source, model Mak 2 (US Inc., San Jose, CA) designed to sputter magnetic materials. The $\mathrm{Ni}$ target used as the cathode in this study was $99.99 \%$ pure, and was $50.8 \mathrm{~mm}$ in diameter and $3.175 \mathrm{~mm}$ in thickness. The base pressure varied between $1 \times 10^{-7}$ and $1 \times 10^{-6}$ torr, and the chamber was baked for about $20 \mathrm{~h}$ by wiring with a couple of heaters before use to get rid of the moisture from the walls of the chamber more efficiently. The cathode power used was 200 or $400 \mathrm{~W}$ and the argon pressure was maintained at 6.0 mtorr during the deposition. High-purity argon was used. A pulsed dc negative bias between 0 and $200 \mathrm{~V}$ was applied during the deposition using an ENI (Fremont, CA) power supply system. The pulse frequency and width were $250 \mathrm{kHz}$ and 1296 ns, respectively. Application of a pulsed supply to bias helps to prevent charge buildup on the substrate, which is a problem in insulating films. Steel substrates or holey carbon copper grids were used as substrates when a substrate bias was applied to ensure good electrical conductivity. Deposition was performed at room temperature ( $T_{\mathrm{s}}=0.17 T_{\mathrm{m}}$ ) or close to liquid nitrogen temperature $\left(T_{\mathrm{s}}=0.04 T_{\mathrm{m}}\right)$. To maintain the substrate at liquid nitrogen temperature during film growth, a separate heat flow path was built with a flat copper plate soldered to a copper tube carrying liquid nitrogen. This was in thermal contact with, but electrically insulated from, the substrate holder by a sheet of Kapton (a polymer, which is stable in vacuum). Liquid nitrogen was passed through the tube for $15 \mathrm{~min}$ before etching to allow sufficient time for cooling of the substrate holder and then continuously flushed until $5 \mathrm{~min}$ after the end of the deposition experiment.

The $\mathrm{Si}$ and steel substrates (in polished condition) were cleaned with an ultrasonic wave generator in baths of acetone and methanol or isopropanol. The salt substrate was cleaned by rubbing on a wet tissue paper 
moistened with distilled water. Prior to deposition, the substrate was etched using an argon plasma at a pressure of $18.0 \mathrm{mtorr}$ and a pulsed dc substrate bias of $-500 \mathrm{~V}$ to sputter clean the substrate surface. The plasma density was enhanced by means of a radio frequency (rf) coil surrounding the region between the target and substrate. The substrate was kept at a distance of $90 \mathrm{~mm}$ from the target. The average deposition rate of the film was estimated to be $1.15 \mathrm{~nm} / \mathrm{s}$ from thickness measurements of all the films at the cathode power of $200 \mathrm{~W}$. The growth rate did not show much variation with change in substrate bias. Ni films grown at room (ambient) temperature will be referred to as "RT" films, while those grown at liquid nitrogen temperature will be referred to as "LN" films.

Some of the Ni films on Si substrate were characterized through $\mathrm{x}$-ray diffraction (XRD) on a Philips $\mathrm{X}$-ray diffractometer (Eindhoven, The Netherlands) showing the relative intensities of various peaks. Singlecrystal $\mathrm{Si}(100)$ peak was avoided by not including the angles around its position in the scan.

$\mathrm{Ni}$ films were floated off in a beaker of water from the $\mathrm{NaCl}$ substrates by partial dissolution of the salt. Fragments of the film were fished on to 200 mesh copper grids and ion milled for a short period at liquid nitrogen temperature to achieve electron transparency. These were used for plan-view imaging. Cross-section specimens were prepared from $\mathrm{Ni}$ films grown on $\mathrm{Si}$ or steel substrates by gluing together small rectangular pieces with the films facing each other, followed by mechanical polishing, dimpling, and ion milling. Ion milling was performed at liquid nitrogen temperature for $1-1.5 \mathrm{~h}$. Transmission electron microscopy (TEM) studies were performed on a Hitachi H-8100 TEM (Hitachi Instruments, Japan) using $200 \mathrm{kV}$ acceleration voltage. Grain size distributions were estimated by dark-field TEM imaging and size measurement of approximately 1000 grains.

Optical microscopy was used to study the surface morphology of RT and LN Ni films of different thicknesses on steel substrates with emphasis on qualitative characterization of porosity size and distribution, defects, and roughness over the entire area. Small depth of field of optical microscope helps in identifying porosities, surface defects, and rough features on surfaces. While use of an atomic force microscope provides data on roughness on an atomic scale, use of optical microscope is a much simpler tool preferred for the purpose of qualitatitive characterization of much larger area of the surfaces where the features of interest have dimensions in or larger than micrometer scale.

Residual stress in the Ni films was determined by measuring the change in the curvature or deflection $\delta$ due to deposition of $\mathrm{Ni}$ of a $50-\mathrm{mm}$ span marked on the $\mathrm{Si}$ wafer cantilever beam used as the substrate. The curvature of the beam was measured using a diamond stylus profilometer. The stress $\sigma$ in the film was calculated from Stoney's equation: ${ }^{32}$

$$
\sigma=B_{\mathrm{s}}\left[4 t_{\mathrm{s}}^{2} / 3 L^{2} t_{\mathrm{f}}\right] \delta
$$

where $B_{\mathrm{s}}$ is the biaxial modulus of the substrate and is given by $E_{\mathrm{s}} /\left(1-v_{\mathrm{s}}\right) ; E_{\mathrm{s}}$ and $v_{\mathrm{s}}$ are Young's modulus and Poisson's ratio of the substrate, respectively; $L$ is the length marked on the beam (50 $\mathrm{mm}$ in this study) whose curvature is measured; $t_{\mathrm{s}}$ and $t_{\mathrm{f}}$ are thickness of the substrate and film, respectively; and $\delta$ is the beam deflection.

The hardness of the Ni films was measured using a UMIS-2000 ultra-microindentation system (Australian Scientific Instruments Pty Ltd., Canberra, Australia) equipped with a Berkovitch diamond indenter. Load selection (in the range of 4-10 $\mathrm{mN}$ ) for hardness measurement was made such that the depth of the indentation did not exceed $10-15 \%$ of the thickness of the film. This procedure was followed to minimize the effect of the substrate on hardness measurements. Around 15 tests were performed on each specimen, and the results were averaged to determine the hardness.

\section{RESULTS AND DISCUSSION}

Some of the Ni films were analyzed using energy dispersive spectroscopy on transmission electron microscopy (TEM) specimens, and the films were found to be pure, with no impurity segregation at grain boundaries. ${ }^{33}$ The films floated from $\mathrm{NaCl}$ substrates showed $\mathrm{Na}$ and $\mathrm{Cl}$ peaks besides $\mathrm{Ni}$, and these are due to substrate residue sticking to the film or copper grid on evaporation of water.

\section{A. Room-temperature films}

\section{Grain morphology and size distribution}

Figures 1(a) and 1(b) are plan-view dark-field TEM images showing the sizes and morphology of grains in the $0.1-\mu \mathrm{m}$-thick RT Ni films made with a cathode power of $200 \mathrm{~W}$ and -100 and $-200 \mathrm{~V}$ substrate bias, respectively. The grain size increases with an increase in the bias from 0 to $-200 \mathrm{~V}$, but shapes remain unchanged in plan-view images. Figure 1(c) shows an electron diffraction pattern from the plan-view TEM specimen of the $\mathrm{Ni}$ film grown using $-100 \mathrm{~V}$ bias, which is typical of the diffraction patterns obtained from the RT Ni films grown using 0-200 V bias. The ring pattern in Fig. 1(c) is characteristic of a specimen with $\langle 111\rangle$ fiber texture with the electron beam parallel to the fiber axis. ${ }^{34}$ XRD observations of such textured samples show a very distinct $\mathrm{Ni}\{111\}$ peak, while the rest of the peaks are insignificant, which is also characteristic of $\langle 111\rangle$ texture in the film. ${ }^{35}$ An example of XRD data showing presence of texture is demonstrated in Table I, where the LN Ni films of $1.5 \mu \mathrm{m}$ thickness have shown strong <111> texture, whereas the RT film of similar thickness does 
(a)
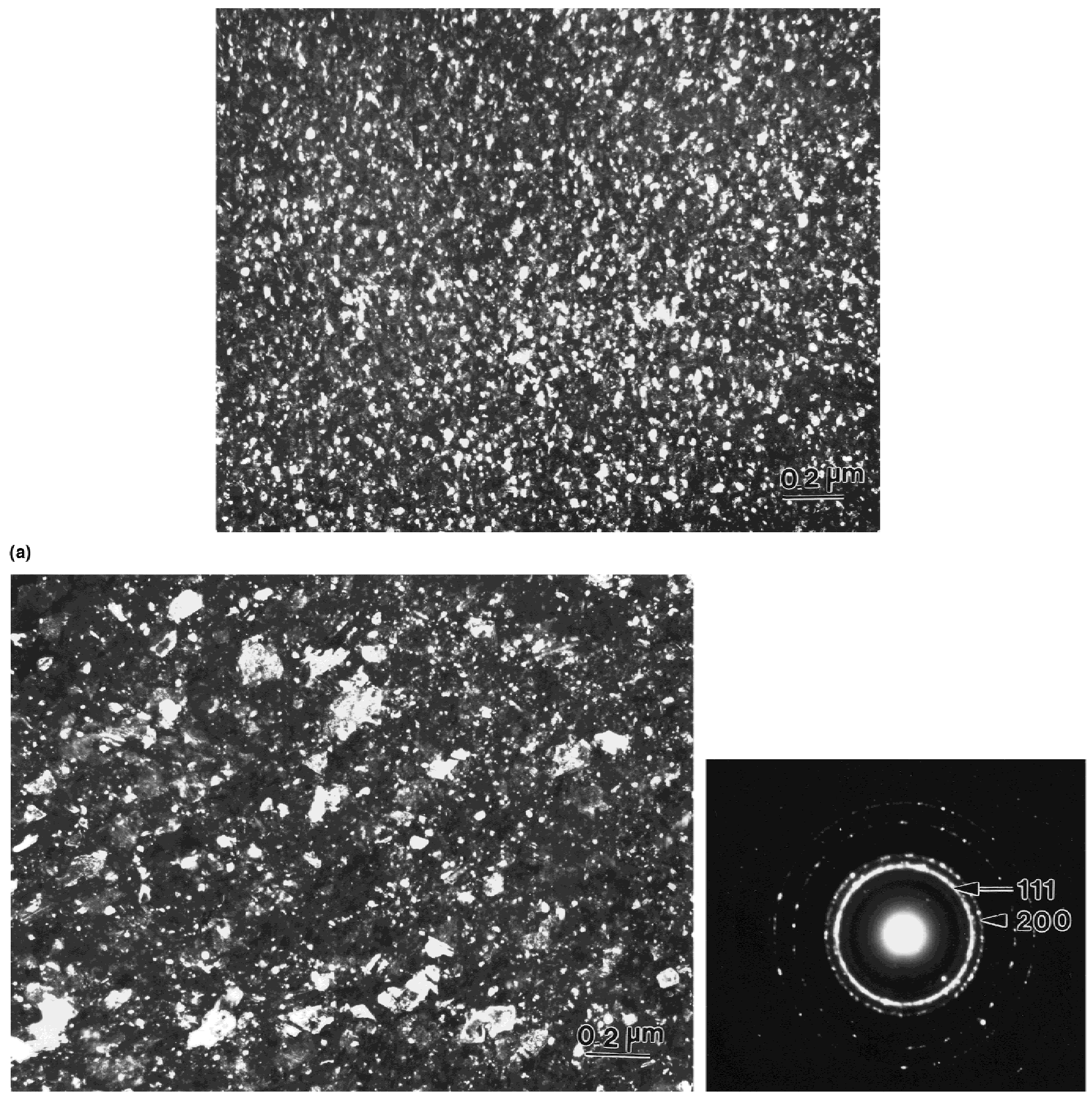

(b)

(c)

FIG. 1. Plan-view grain structure in $0.1-\mu \mathrm{m}$-thick RT Ni film grown at a cathode power of $200 \mathrm{~W}$ : dark field TEM images of films grown at substrate bias of (a) $-100 \mathrm{~V}$, and (b) $-200 \mathrm{~V}$; (c) typical electron diffraction pattern from film grown at $-100 \mathrm{~V}$ bias.

not show. JCPDS XRD data ${ }^{36}$ for Ni with random orientation of grains have been also included in Table I for comparison. Data in Table I also imply that $\langle 111\rangle$ texture is lost with the increase in thickness in the RT films, and this observation will be discussed later in this section. $<111>$ texture is present, irrespective of whether the film was grown on salt or Si. Texturing of metallic films with nano-sized equiaxed grains, grown at low temperatures has been reported in the past. ${ }^{37-40}$ As the $\{111\}$ planes are the most densely packed in the face-centeredcubic (fcc) lattice, the grains with $\{111\}$ planes parallel to the surface of the film will have minimum surface and interface energy. ${ }^{40}$ Further electron diffraction studies have revealed that the $\langle 111\rangle$ texture is weaker in the film grown with $-200 \mathrm{~V}$ substrate bias as compared to those grown at a lower or no bias. The loss of texture at higher bias is possibly due to increased adatom mobility causing recrystallization as discussed later in this paper. 
Figure 2 shows the plan-view grain size distributions of the $0.1-\mu m$-thick RT Ni films with various substrate bias voltages, obtained by TEM examination of planview specimens. The grain size distributions follow a lognormal relationship. The lognormal distribution function, $\mathrm{f}(x)$ is expressed as ${ }^{41}$

$\mathrm{f}(x)=1 /\left\{\mathrm{V}(2 \pi) x s_{\ln x}\right\} \cdot\left[\exp \left\{-1 / 2\left(\left(\ln x-m_{\ln x}\right) / s_{\ln x}\right)^{2}\right\}\right]$,

where $x$ represents either grain size or grain volume, and the $m_{\ln x}$ and $s_{\ln x}$ are respectively the mean and standard deviations of $\ln x$, and should not be confused with the logarithms of the mean and of the standard deviation of a normal distribution, respectively. The mean grain size in the lognormal distribution is given by:

$$
m_{x}=\exp \left(m_{\ln x}+s^{2}{ }_{\ln x} / 2\right),
$$

The mode and mean values of the grain size distributions shown in Fig. 2 are presented in Table II. The mean grain sizes $(9-25 \mathrm{~nm})$ observed here are smaller than the value of minimum size reported in the studies of the electron beam-evaporated $\mathrm{Ni}$ films by Grovenor et $a l^{20}$ The grain size distributions of $\mathrm{Ni}$ films grown using -100 or $-150 \mathrm{~V}$ substrate bias are almost identical (Fig. 2). But it is also clear that the the mode and mean values of the grain size distributions increase gradually with an increase in the bias voltage from 0 to $-200 \mathrm{~V}$. This increase is believed to be due to the substrate heating and increased diffusivity in the film during deposition, brought about by increased bombardment of the film by argon ions, and is discussed later in this section.

Figure 3(a) is a dark-field cross-section TEM micrograph of a $2.3-\mu \mathrm{m}$-thick RT Ni film grown without applying any substrate bias voltage, using a cathode power of $200 \mathrm{~W}$. It shows columnar grain formation, followed by an equiaxed grain morphology near the free surface of the film, $0.2-0.4 \mu \mathrm{m}$ away from the film-substrate interface. In contrast, the plan-view TEM studies did not reveal the columnar grains, and only equiaxed morphology similar to that observed in the film grown with -100 $\mathrm{V}$ bias [Fig. 1(a)] was observed. The observation of columnar structure is somewhat similar to the grain structure in sputtered films grown without a bias ${ }^{15,21-23,42}$ but not quite the same as in electron-beam-evaporated $\mathrm{Ni}$ films. ${ }^{20}$ Columnar porosities could be observed between the grains in the bright-field TEM micrograph as shown in Fig. 3(b), similar to observations of Misra and coworkers. ${ }^{15,42}$ A columnar structure occurs because the islands of sputtered atoms, which are distinct from one another during nucleation, grow in the vertical direction. The nucleation of more islands is prevented in the process by intergrain shadowing leading to tapered crystallites, and the grain morphology becomes columnar. In this situation, intergrain boundaries are full of voids, and are not true grain boundaries. ${ }^{31,43}$ The occurrence of equiaxed grains above the columnar grains with similar orientation as shown in the dark-field image of Fig. 3(a) implies that columnar growth is arrested at some point, which is followed by secondary nucleation of fresh islands on the close-packed $\{111\}$ facets of columnar grains. Fuks et al. ${ }^{44}$ have shown that the effective activation energy $(4 \mathrm{kcal} / \mathrm{mol})$ for migration and redistribution of an atom in a Ni film during deposition under conditions of disordered atomic structure and lower density of atomic packing is much lower than self diffusion of Ni in bulk single crystals $(60 \mathrm{kcal} / \mathrm{mol})$ and polycrystals $(30 \mathrm{kcal} / \mathrm{mol})$ between 20 and $200{ }^{\circ} \mathrm{C}$. The process of atomic redistribution in the film is further aided by the bombardment of neutral argon atoms reflected from

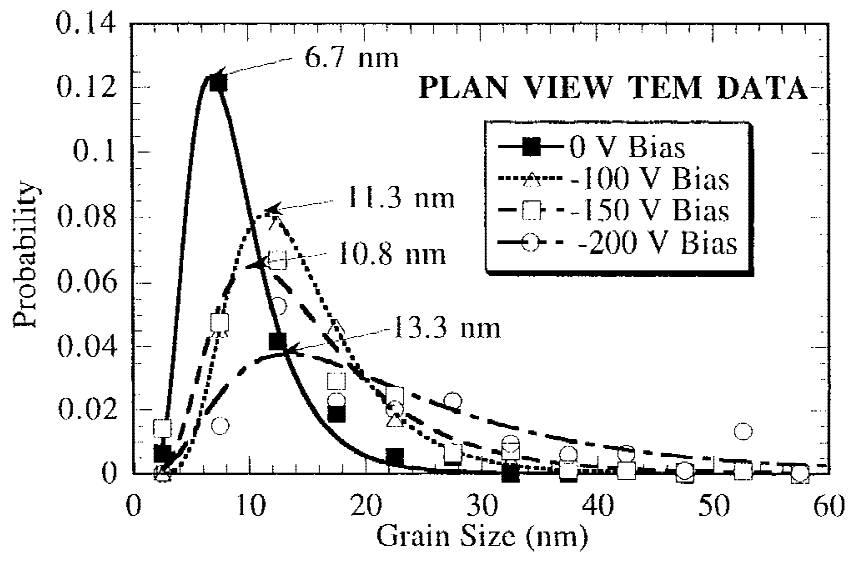

FIG. 2. Lognormal grain size distributions of RT Ni films grown at a cathode power of $200 \mathrm{~W}$ obtained by TEM examination of plan-view specimens.

TABLE I. Data from a typical XRD pattern of LN and RT Ni films of 1.5- $\mu \mathrm{m}$ thickness grown using $-100 \mathrm{~V}$ bias on Si substrate, obtained using $\mathrm{Cu}, \mathrm{K}_{\alpha}$ radiation. The planes $(h k l)$, interplanar spacing $(d)$, peak heights and background, corresponding relative intensities (RI), and RI for random orientation (JCPDS XRD data ${ }^{36}$ ), are shown.

\begin{tabular}{lllcrr}
\hline \hline$h k l$ & $d(\mathrm{~nm})$ & $\begin{array}{c}\text { LN film peak height, } \\
\text { background (counts/s) }\end{array}$ & $\begin{array}{c}\text { LN film RI } \\
I / I_{1}(\%)\end{array}$ & $\begin{array}{c}\text { RT film peak height, } \\
\text { background (counts/s) }\end{array}$ & $\begin{array}{c}\text { RT film RI } \\
I / I_{1}(\%)\end{array}$ \\
\hline 111 & 2.034 & $228465.44,49.24$ & 100 & $2966.7,52.31$ & $\begin{array}{c}\text { RI random } \\
\text { orientation } \\
I / I_{1}(\%)\end{array}$ \\
200 & 1.762 & $448.02,49.24$ & 0.20 & $2220.26,52.31$ & 100 \\
220 & 1.246 & $61.46,48.58$ & 0.03 & $63.57,58.35$ & 74.8 \\
311 & 1.0624 & $54.14,38.13$ & 0.02 & $118.37,39.43$ & 2.1 \\
\hline \hline
\end{tabular}


the target. Hence the adatom mobility of $\mathrm{Ni}$ atoms on its own surface during deposition at room temperature $\left(27^{\circ} \mathrm{C}\right.$ or $0.17 T_{\mathrm{m}}$ ) is probably high enough for redistribution of impinging atoms, nucleation, and growth of the islands into equiaxed grains. The adatom mobility on the unbiased Si substrate at room temperature may not be high enough, discouraging lateral growth and leading to columnar growth in the direction of flux.

Application of $-100 \mathrm{~V}$ bias to the substrate leads to formation of equiaxed grain morphology as shown in Fig. 4(a), a dark-field cross-section TEM image obtained from a $0.1-\mu \mathrm{m}$-thick Ni film grown using $200 \mathrm{~W}$ cathode power and $-100 \mathrm{~V}$ bias on Si substrate. The grains are spherical or equiaxed. High-resolution electron microscopy studies on cross-section specimens, some of which have been published elsewhere ${ }^{45}$ have also shown that the grains are spherical and equiaxed [Fig. 4(b)]. The elimination of columnar grain growth on application of bias is consistent with the observations of Mattox and coworkers. ${ }^{22,23}$ Figure 4(c) compares the lognormal grain size distributions of a Ni film obtained from planview and cross-section TEM imaging. The grain size distribution obtained from cross-section TEM is similar to that obtained from plan-view imaging

In the present study, it has been observed that the grains are mostly columnar when no bias is used, and equiaxed on application of a substrate bias. If the structure is columnar, the density is likely to be lower because of intercolumnar porosities, and the mechanical properties will be worse in the transverse direction. The momentum of the argon ions striking the film is used to break the columnar structure growing from the islands on the substrate by knocking the atoms into neighboring valleys. Increase in the negative bias voltage causes a higher rate of resputtering of the film by argon atoms. Chopra $^{46}$ observed large-scale movement of small islands $(<10 \mathrm{~nm})$ over distances up to $100 \mathrm{~nm}$, coalescence as well as break-up of islands, flattening of islands, etc. in a lead thin film on irradiation with electron beam inside the TEM. Application of negative bias and continuous redistribution of adsorbed atoms on the substrate increases the number of nucleation sites per unit area and the density of the film. An increase in the density of the metallic films on application of negative substrate bias has also been reported by Mattox and coworkers. ${ }^{22,23} \mathrm{On}$ the other hand, enhanced sputtering of the film also leads to heating by transfer of momentum and energy.

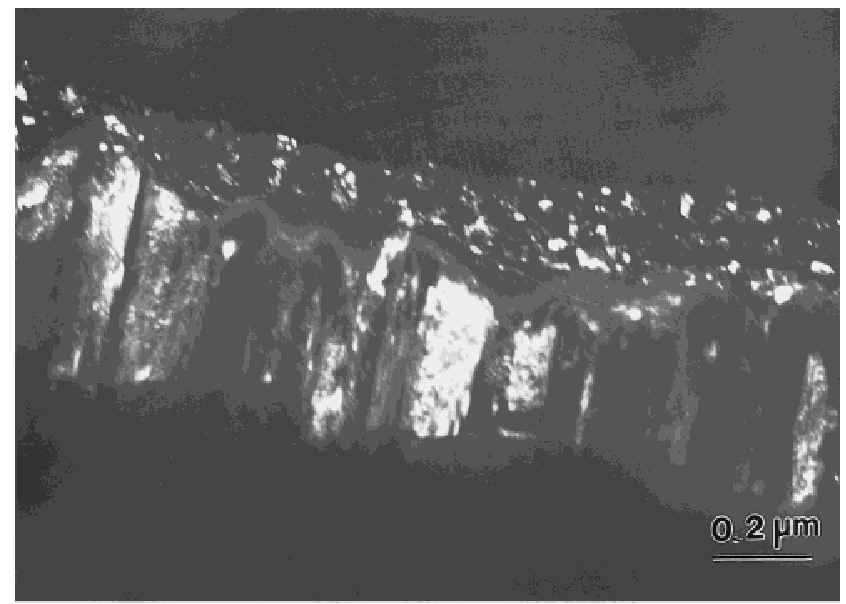

(a)

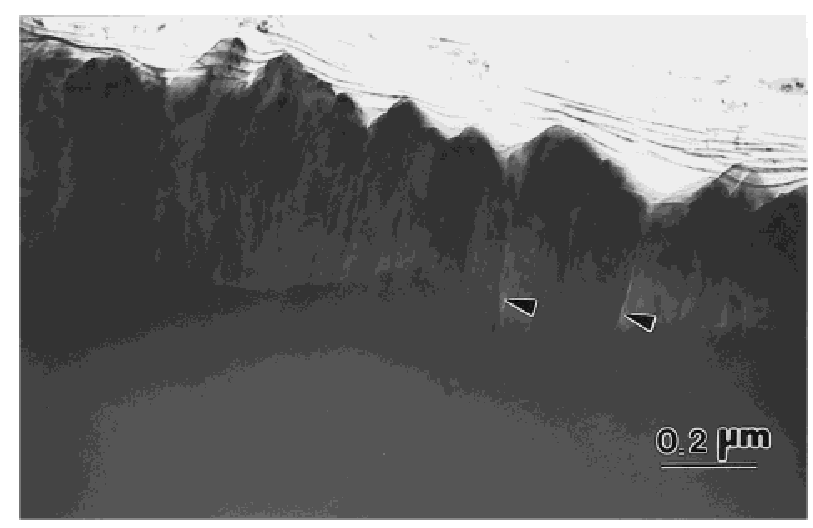

(b)

FIG. 3. Cross-section TEM image of RT Ni film grown using a cathode power of $200 \mathrm{~W}$ and no substrate bias: (a) dark-field image showing columnar grains below and equiaxed grains on the top, and (b) bright-field image showing columnar porosities (shown with arrows).

TABLE II. Grain size (GS) distributions data of Ni films of thickness $\leqslant 0.1 \mu \mathrm{m}$ grown by magnetron sputtering. The cathode power used was $200 \mathrm{~W}$ (plan-view TEM data).

\begin{tabular}{rlrr}
\hline \hline $\begin{array}{c}\text { Bias } \\
(\mathrm{V})\end{array}$ & \multicolumn{1}{c}{ Temperature } & $\begin{array}{c}\text { Grain size } \\
\text { mode }(\mathrm{nm})\end{array}$ & $\begin{array}{c}\text { Grain size } \\
\text { mean }(\mathrm{nm})\end{array}$ \\
\hline 0 & room temperature & 6.8 & 9.0 \\
-100 & room temperature & 11.4 & 14.5 \\
-150 & room temperature & 10.8 & 15.5 \\
-200 & room temperature & 13.7 & 24.8 \\
0 & liquid nitrogen temperature & 10.0 & 1.0 \\
-100 & liquid nitrogen temperature & 7.5 & 11.3 \\
-150 & liquid nitrogen temperature & 6.0 & 11.5 \\
-175 & liquid nitrogen temperature & 4.3 & 12.0 \\
-200 & liquid nitrogen temperature & 6.0 & 13.2 \\
\hline \hline
\end{tabular}




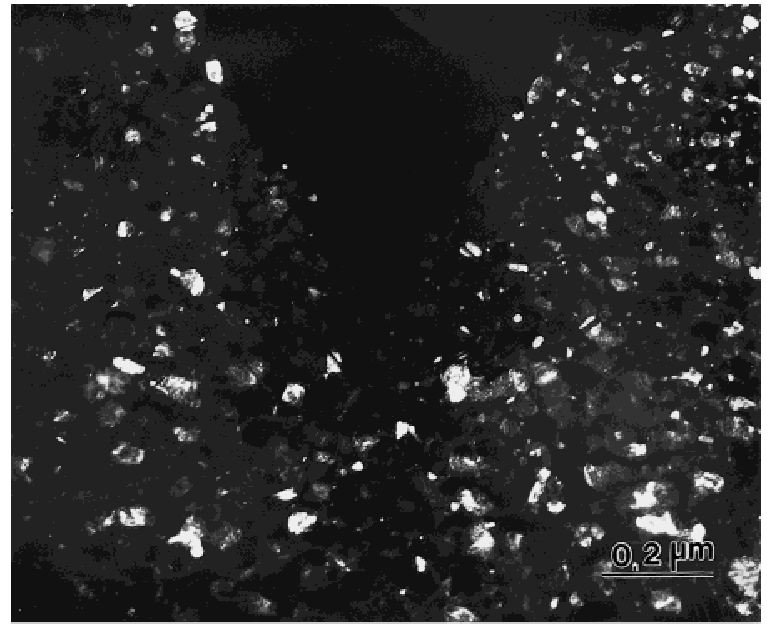

(a)

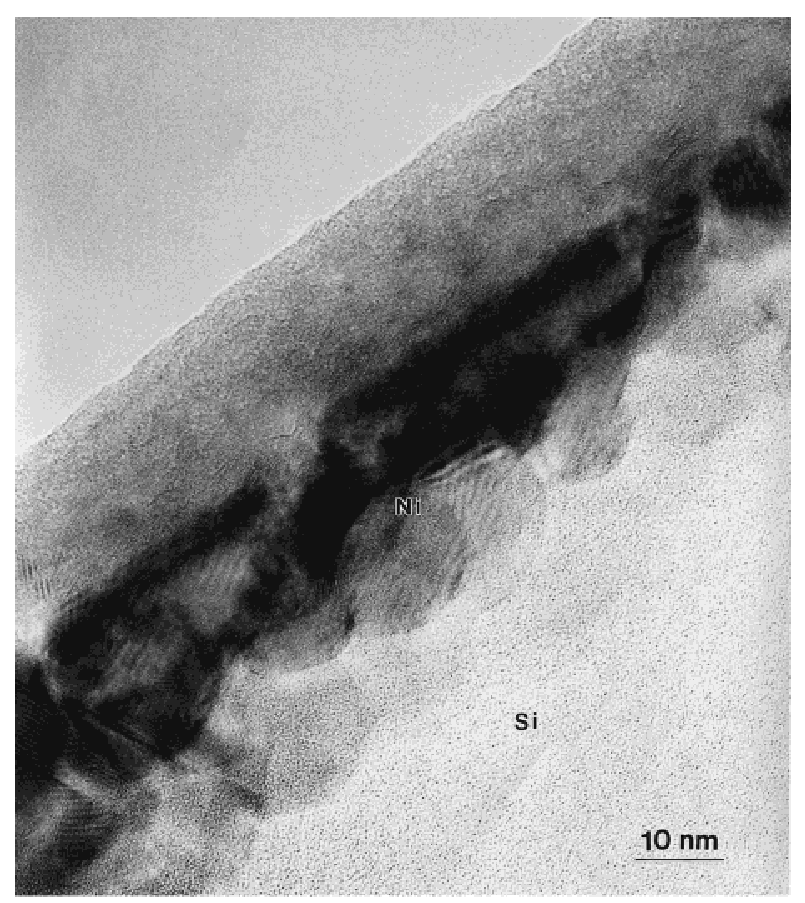

(b)

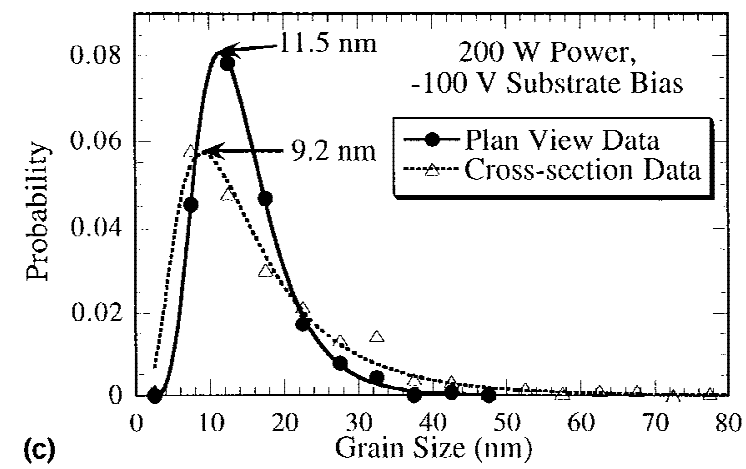

FIG. 4. RT Ni film grown using a substrate bias of $-100 \mathrm{~V}$ : (a) dark-field TEM image from a cross-section specimen, (b) high-resolution TEM micrograph showing equiaxed grain structure, (c) lognormal grain size distribution obtained from cross-section TEM studies as compared with that obtained from plan-view TEM observations.
Whenever a bias was used, a warm substrate was observed during the venting of the chamber about $15 \mathrm{~min}$ after the end of deposition. The heating results in enhanced diffusivity and grain boundary mobility in the film, leading to grain growth and widening of the grain size distribution, as has been noticed in the $\mathrm{Ni}$ films [Figs. 1(a) and 1(b) and Fig. 2]. Grain growth has been observed at temperatures as low as $0.2 T_{\mathrm{m}}$ in the case of high-purity gold films ${ }^{35}$ and also on increasing substrate temperatures of vapor-deposited Ni films from the subzero range. ${ }^{18}$ Increased high-energy ion bombardment also leads to multiplication of point defects, which enhance grain boundary mobilities, and consequently grain growth. ${ }^{47-50}$

Grain growth was also observed with increase in thickness of the films, which is in agreement with that reported in the literature. ${ }^{46}$ Figures 5(a) and 5(b) are plan-view TEM micrographs of 0.1 and $1.9 \mu \mathrm{m}$ thick RT $\mathrm{Ni}$ films respectively, grown using a cathode power of $200 \mathrm{~W}$ and substrate bias of $-150 \mathrm{~V}$. As a thicker film needs longer time to be processed, diffusion controlled grain growth takes place effectively by the mechanism discussed above. Also, increase in grain size with increase in film thickness is more pronounced when adatom mobility is high; ${ }^{46}$ that is, when higher negative substrate bias is used. The $\langle 111\rangle$ texture observed in the diffraction pattern of thin films ( $0.1 \mu \mathrm{m}$ in thickness) was not observed during TEM studies of the 1.9- $\mu \mathrm{m}$-thick $\mathrm{Ni}$ film, suggesting that texture is weakened during recrystallization and grain growth. Table I shows that (200) peak is stronger than that expected for random orientation of grains in the RT Ni film of $1.5 \mu \mathrm{m}$ thickness grown at $-100 \mathrm{~V}$ bias, which suggests that a tendency towards $\langle 100\rangle$ texture develops with grain growth and increase in film thickness, which needs further investigation.

Figure 6 is a bright-field TEM image from a crosssection specimen of a $0.2-\mu \mathrm{m}$-thick Ni film grown using $400 \mathrm{~W}$ power and $-100 \mathrm{~V}$ substrate bias, showing the tendency of grains to grow in a columnar fashion. The observation of columnar grains in Fig. 6 is in contrast to the equiaxed grain structure observed in crosssection TEM specimens of a Ni film grown using $200 \mathrm{~W}$ power and $-100 \mathrm{~V}$ substrate bias voltage [Figs. 4(a) and 4(b)]. This suggests that a higher bias is required to prevent columnar grain growth when a higher target power is used. Higher target power enhances the flux of the sputtered Ni atoms, while the energy of the impinging atoms is practically unchanged. The growth rate of the film is proportional to the power used for the magnetron source, and the rate of resputtering of the film needs to be enhanced at the same rate. In the absence of adequate resputtering, the impinging $\mathrm{Ni}$ atoms are not redistributed and add on to the existing columns. Bland et al. ${ }^{23}$ have reported that a minimum ion/depositing-atom ratio is 
needed to be effective in disruption of the columnar morphology. On the basis of a systematic investigation of bias sputtered $\mathrm{Cu}$ at low $T_{\mathrm{s}} / T_{\mathrm{m}}$, Thornton ${ }^{51}$ found that suppression of columnar growth with "open boundaries" requires an ion bombardment flux adequate to backsputter a significant fraction of the incident coating flux (30$60 \%$ ). It is not known, whether with increase in thickness, if the columnar growth would stop and equiaxed grains would form as has been shown in Fig. 3(a). It should also be noted that the microstructure in Fig. 6 does not show columnar porosity as observed in the Ni film grown without a substrate bias, probably due to the limited increase in adatom mobility from application of substrate bias.

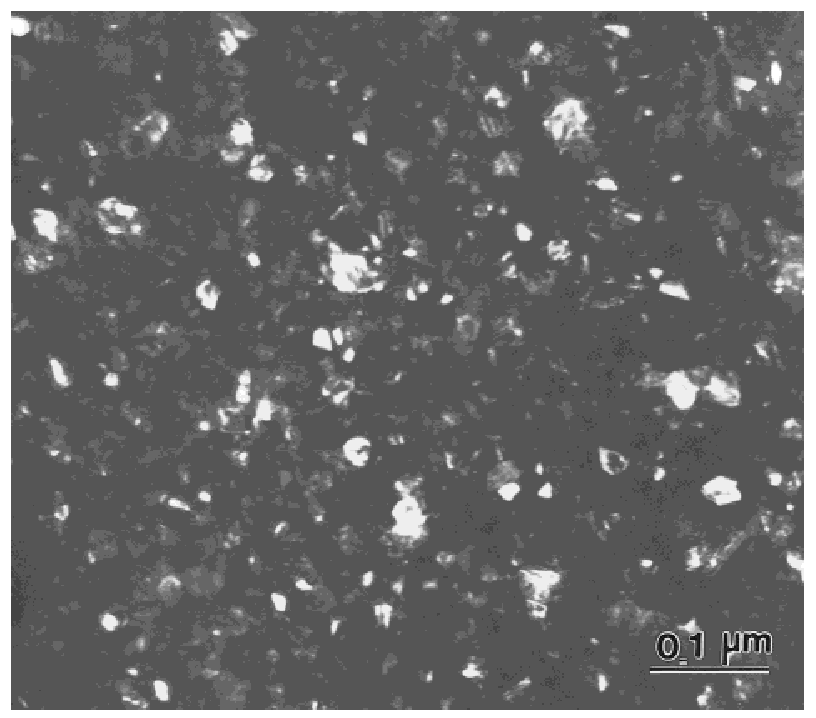

(a)

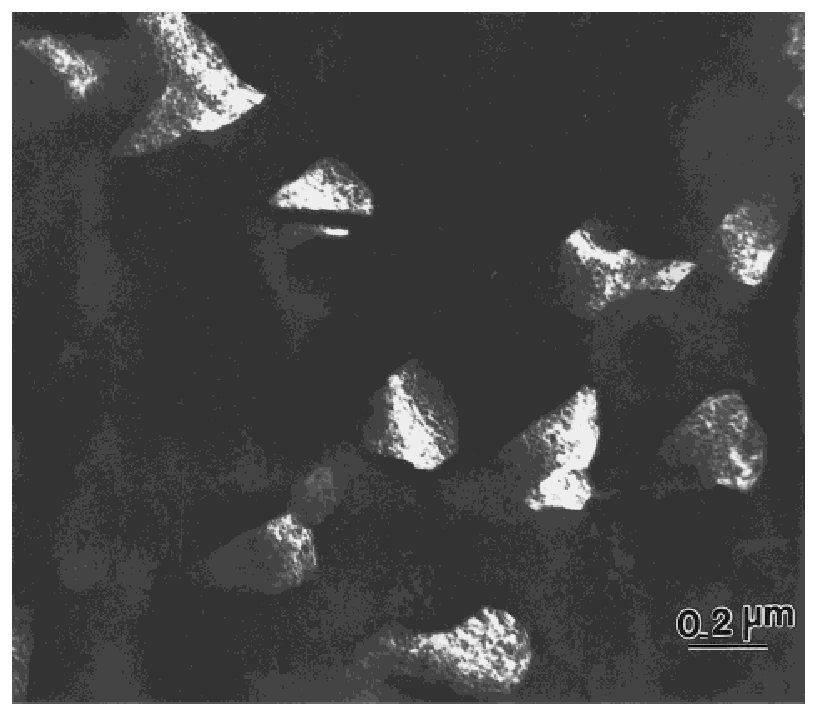

(b)

FIG. 5. Dark-field plan-view TEM images of RT Ni films grown using a cathode power of $200 \mathrm{~W}$ and substrate bias of $-150 \mathrm{~V}$, with thickness of (a) $0.1 \mu \mathrm{m}$ and (b) $1.9 \mu \mathrm{m}$.

\section{Surface Topography and Pore Distribution}

Figures 7(a)-7(c) show the surfaces of the $2.0-\mu \mathrm{m}$ thick Ni films grown at room temperature, using substrate bias of $0 \mathrm{~V},-150 \mathrm{~V}$, and $-200 \mathrm{~V}$, respectively. It is quite obvious that the surface of the film grown at 0 bias voltage is more porous than those made at higher bias voltages. The films grown at $0 \mathrm{~V}$ and $200 \mathrm{~V}$ bias appear to have a rough topography. The rough surface and porosities in the film grown at $0 \mathrm{~V}$ bias [Fig. 7(a)] are attributed to the fact that the grains are columnar and tapered [Fig. 3(a)]. The surface porosities are much larger than the intercolumnar or grain boundary voids [Fig. 3(b)], many of which are of atomic dimensions (nanopores) and the origin of these voids has been discussed earlier in this paper. The pores grow larger as the vacancies trapped in the grain boundaries have significant mobility and coalesce. A reduction of surface-tovolume ratio of the pores is favored by reduction in the surface energy. Grain boundary nanopores could be seen during both plan-view and cross-section TEM investigation of films grown without bias. Closure of grain boundary nanopores can lead to large residual stresses in the films, as has been explained later in this paper. The larger pores on the surface are due to (i) growth of larger intercolumnar pores at the expense of smaller ones to reduce surface energy, as well as (ii) entrapment of argon gas in the film during deposition and subsequent escape from the surface. The argon atoms reaching the film deposited in $0 \mathrm{~V}$ bias condition are those reflected from the target. Application of a moderate bias would reduce entrapment of argon because resputtering with argon ions would discourage sticking of neutral argon atoms to the film. On the other hand, an increase in bias can increase argon entrapment. In Ni films sputter deposited at various temperatures, it was found that argon entrapment is

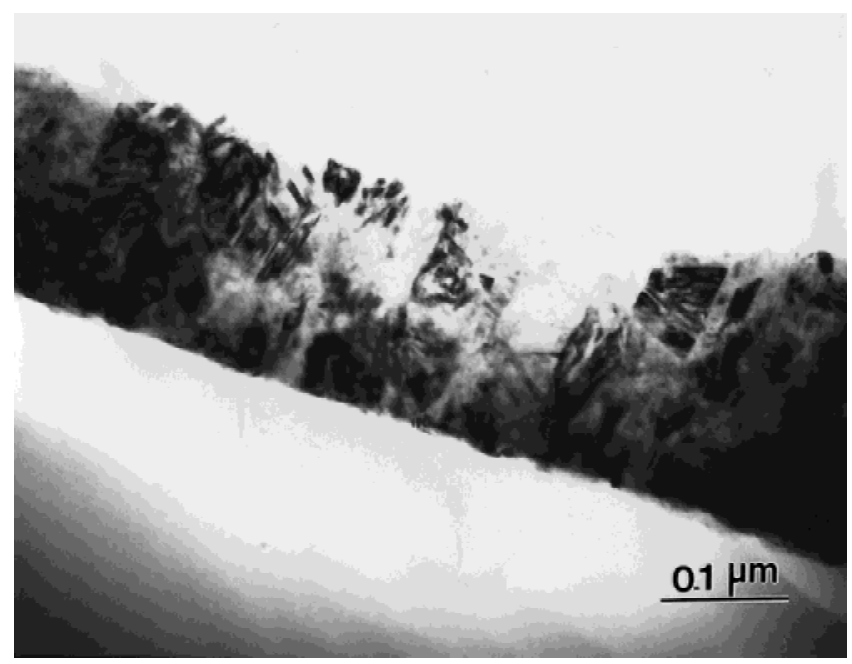

FIG. 6. Bright field cross-section TEM image of RT Ni film grown using a cathode power of $400 \mathrm{~W}$ and substrate bias of $-100 \mathrm{~V}$. 


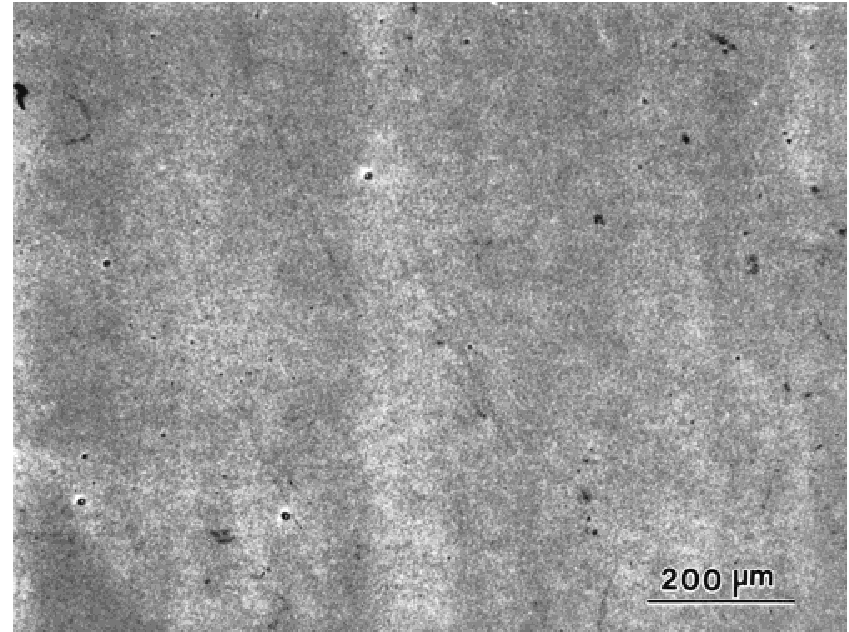

(a)

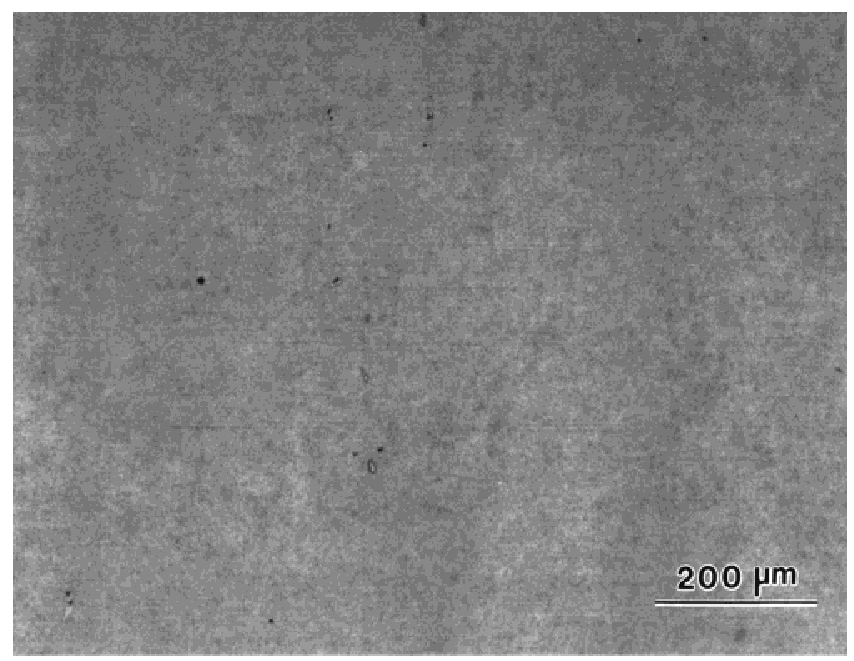

(b)

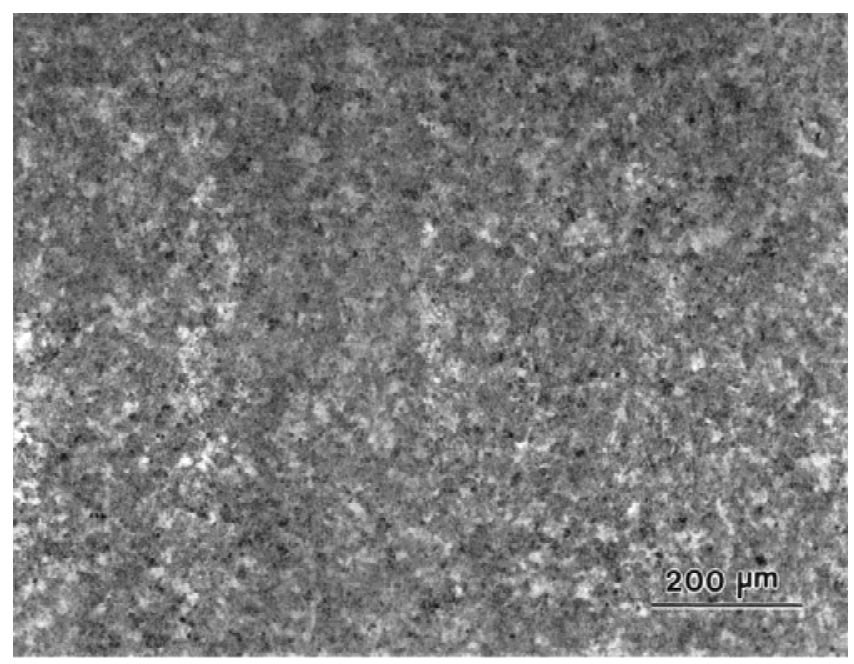

(c)

FIG. 7. Optical micrographs showing the surfaces of 2.0- $\mu$ m-thick RT Ni films grown at a cathode power of 200 Wand a substrate bias of (a) $0 \mathrm{~V}$, (b) $-150 \mathrm{~V}$, and (c) $-200 \mathrm{~V}$. the least at $-100 \mathrm{~V}$ bias and increases with decreasing or increasing bias. ${ }^{52}$ The surfaces of films grown at $-100 \mathrm{~V}$ or $-150 \mathrm{~V}$ bias were neither very rough nor very porous [Fig. 7(b)].

On the other hand, a higher degree of resputtering by argon ions is responsible for the rough film surface obtained from the application of $-200 \mathrm{~V}$ substrate bias. With an increase in the energy of resputtering argon ions, a large concentration of point defects are created, such as displaced $\mathrm{Ni}$ atoms (self-interstitials) and vacancies constituting of Frenkel pairs, and argon atoms are trapped. The self-interstitials and vacancies form clusters, and steps are formed on the surface. Garison and Winograd ${ }^{53}$ have shown that clusters form by rearrangement of constituent atoms with respect to the original surface positions within a localized region of the order of a few angstroms. Line defects such as Frank loops ${ }^{54}$ on $\{111\}$ planes have also been observed on Ni surfaces after ion bombardment. The film roughness also increased with increasing thickness because further growth of the film would maintain the topographic profile of the underlying layer and would form more steps on the surface due to continued ion bombardment. Increase in roughness with thickness will be discussed further in Sec. III. B. 2. on surface topography and pore distribution of LN Ni films.

\section{B. Films grown at liquid nitrogen temperature}

\section{Grain morphology and size distribution}

Figures 8(a) and 8(b) show plan-view dark-field images of grains in the $0.1-\mu \mathrm{m}$-thick LN Ni films grown on holey carbon copper grids at a target power of $200 \mathrm{~W}$ and substrate bias of $-100 \mathrm{~V}$ and $-200 \mathrm{~V}$, respectively. The grain structure and sizes observed in plan-view TEM did not change much with change in substrate bias, unlike what was seen in the RT Ni films [Figs. 1(a) and 1(b)]. Observation of electron diffraction patterns of Ni films grown at all substrate biases showed the tendency of $<111>$ texturing in the grain structure [Fig. 8(c)], as in the $0.1-\mu \mathrm{m}$-thick RT Ni films. In this case too, the closepacked $\{111\}$ planes were the most preferred from surface energy considerations. The XRD pattern of 1.5- $\mu$ m-thick $\mathrm{LN}$ film grown at $-100 \mathrm{~V}$ substrate bias has also shown evidence of $\langle 111\rangle$ texture (Table I), where peaks other than $\{111\}$ are insignificant. Figures 9(a) and 9(b) are cross-section TEM images of LN Ni films grown at a target power of $200 \mathrm{~W}$ and substrate bias of $0 \mathrm{~V}$ and $-100 \mathrm{~V}$, having the thickness of $2.1 \mu \mathrm{m}$ and $1.5 \mu \mathrm{m}$, respectively. While plan-view imaging of a LN Ni film grown at $0 \mathrm{~V}$ bias showed an equiaxed grain structure similar to that in Figs. 8(a) and 8(b), cross-section imaging showed a columnar grain structure along with some equiaxed coarse grains [Fig. 9(a)]. Some of the columnar grains almost spanned the thickness of the film, as observed by Dahlgren et al. $^{21}$ in Ni films sputter- 


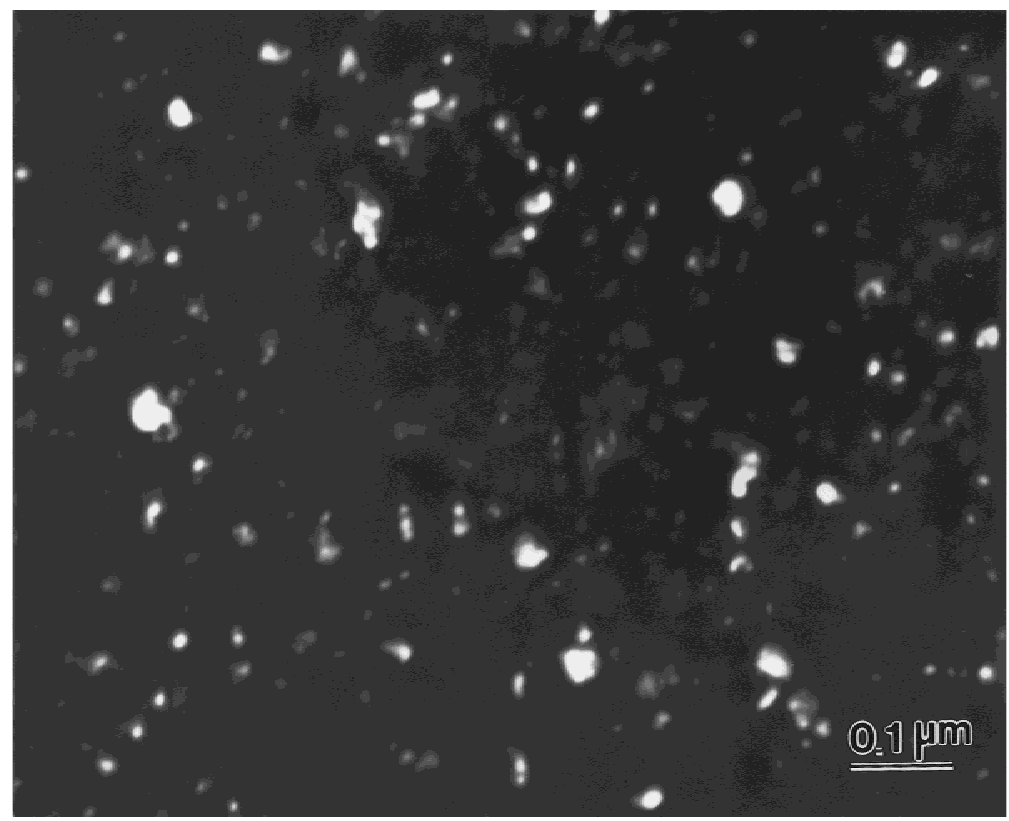

(a)

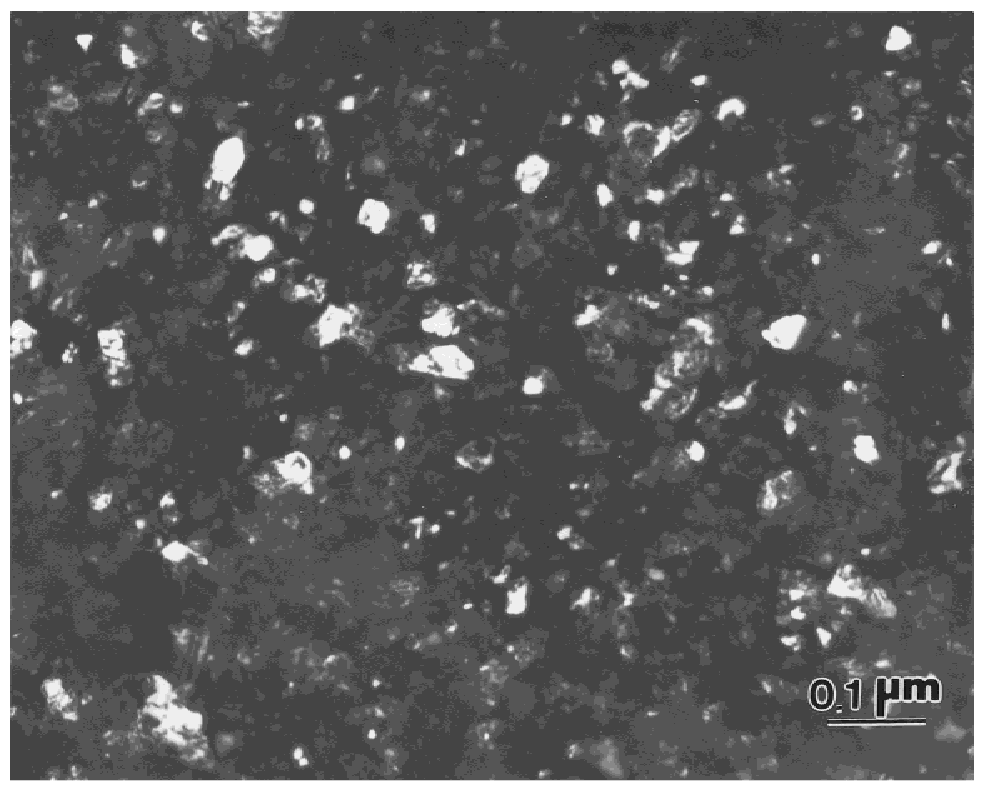

(b)

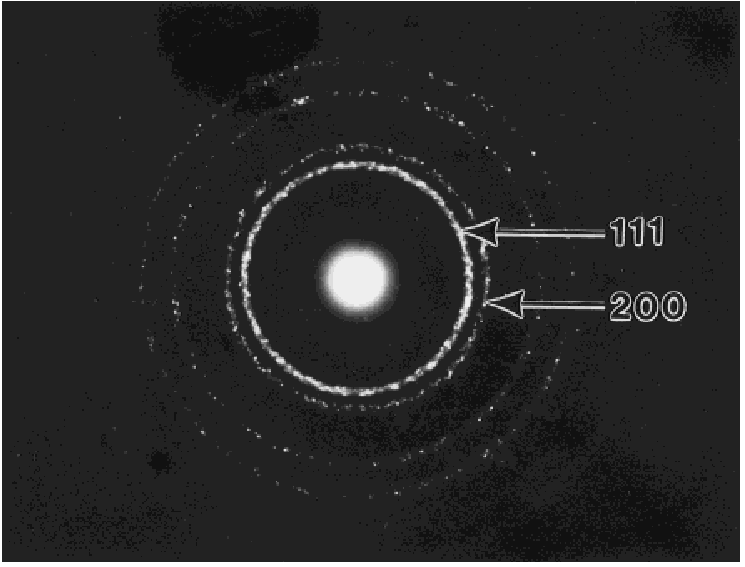

(c)

FIG. 8. Plan-view grain structure of $0.1-\mu \mathrm{m}$-thick LN Ni films grown at $200 \mathrm{~W}$ target power: dark-field TEM images corresponding to substrate bias of (a) $-100 \mathrm{~V}$ and (b) $-200 \mathrm{~V}$; (c) electron diffraction pattern corresponding to bias of $-100 \mathrm{~V}$.

deposited at $-150{ }^{\circ} \mathrm{C}$. The grain structure in the Ni films grown at $-100 \mathrm{~V}$ substrate bias and above was equiaxed, as shown in Fig. 9(b). Detailed TEM studies revealed that a small fraction of the grains in the film grown using $-100 \mathrm{~V}$ substrate bias possessed an aspect ratio greater than one with the elongation in the growth direction, indicating a tendency for columnar growth. Films grown at low substrate temperatures $\left(<0.1 \mathrm{~T}_{m}\right)$ are more likely to have columnar structure as a consequence of atomic shadowing along with low adatom mobilities. ${ }^{31,43} \mathrm{Co}-$ lumnar grain structure was not observed at all during cross-section TEM examination of the LN Ni film grown using $-150 \mathrm{~V}$ substrate bias. Increase in the bias voltage and ion bombardment of the film leads to a more equiaxed grain structure. Application of a negative substrate bias voltage also increases the number of nucleation sites, which prevents columnar growth. This is observed even in the case of relatively thick $(7-8 \mu \mathrm{m})$ films. The films appeared without porosity in TEM observations of plan-view and cross-section specimens, using underfocussed images, implying densification of the film by the application of a substrate bias. The grain size 
distributions of the LN Ni films from plan-view TEM studies have been plotted using the lognormal relationship [Eq.(2)] and are shown in Fig. 10(a). The mode and mean of the grain size distributions are shown in Table II. The grain sizes (both mode and mean) are obviously smaller in the LN Ni films, except when no bias is used. There is no sharp difference in grain sizes at liquid nitrogen temperature with change in substrate bias voltage [Fig. 10(a)], which is similar to the observations of Grovenor et al. ${ }^{20}$ However, it is interesting to note that the mode of the grain size distribution becomes finer with an increase in the substrate bias up to a voltage of -175 $\mathrm{V}$, beyond which it becomes larger, while the mean of the distributions does not vary much. Figure 10(b) shows the comparison of grain size distributions obtained from plan-view and cross-section TEM studies of the LN Ni

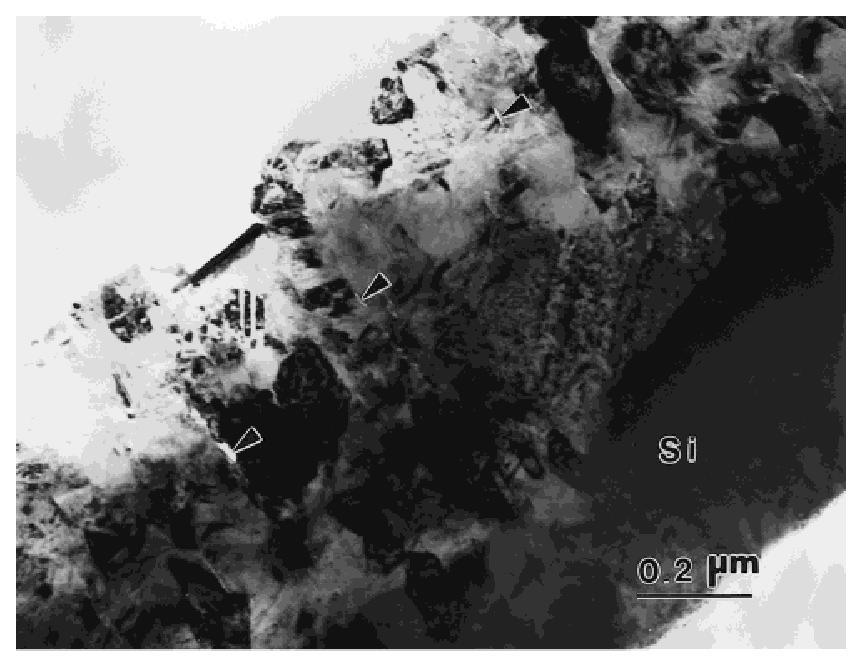

(a)

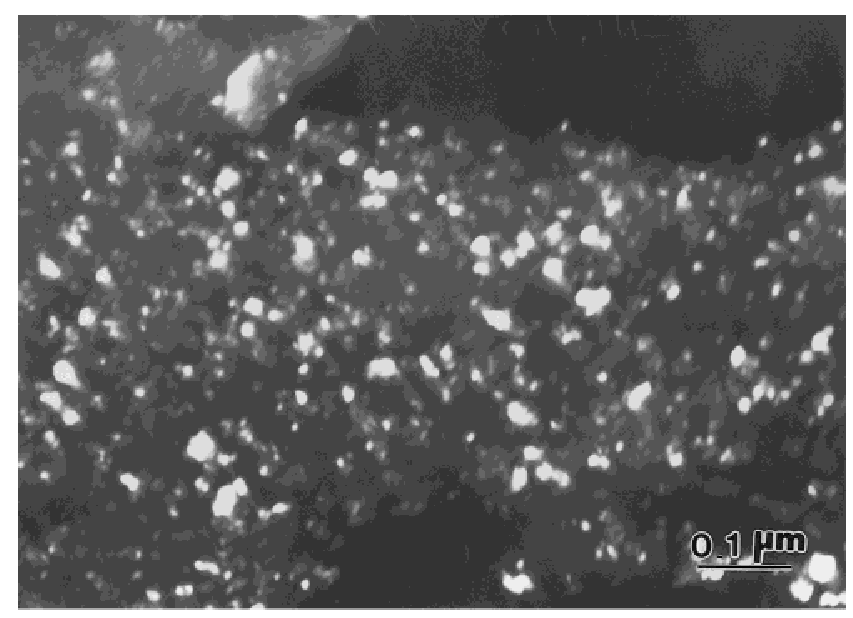

(b)

FIG. 9. Cross-section TEM images of LN Ni films grown using a cathode power of $200 \mathrm{~W}$ : (a) bright field image at $0 \mathrm{~V}$ bias, and (b) dark field image at $-100 \mathrm{~V}$ bias. The grains grown with a substrate bias are equiaxed and columnar without bias. Columnar porosities are indicated by arrows in Fig. 9(a). film grown at a bias voltage of $-150 \mathrm{~V}$. The mode of both the grain size distributions is $6.0 \mathrm{~nm}$, implying once again that the grains are equiaxed in shape. The mean grain sizes are only slightly different; that is, $11.5 \mathrm{~nm}$ in case of plan-view sample, and $9.0 \mathrm{~nm}$ in case of the cross-section sample.

The grain sizes of films grown at liquid nitrogen temperature are finer than those of films processed at room temperature for deposition with a negative substrate bias. Even the grain size distributions are narrower in the films grown at liquid nitrogen temperature, and the difference with the grain size distributions of the RT films increases with increase in the substrate bias. The comparison between the grain size distributions of RT and LN films is shown in Fig. 11. As has been discussed earlier, a higher bias voltage implies a larger degree of resputtering of the film by argon ions, and hence higher atomic mobility and also a rise in temperature during processing of RT films. This could lead to grain growth. Use of liquid nitrogen temperature prevents substrate heating due to high-energy collisions. However, the transfer of momentum from argon ion bombardment still enhances the mobility of the adsorbed atoms.
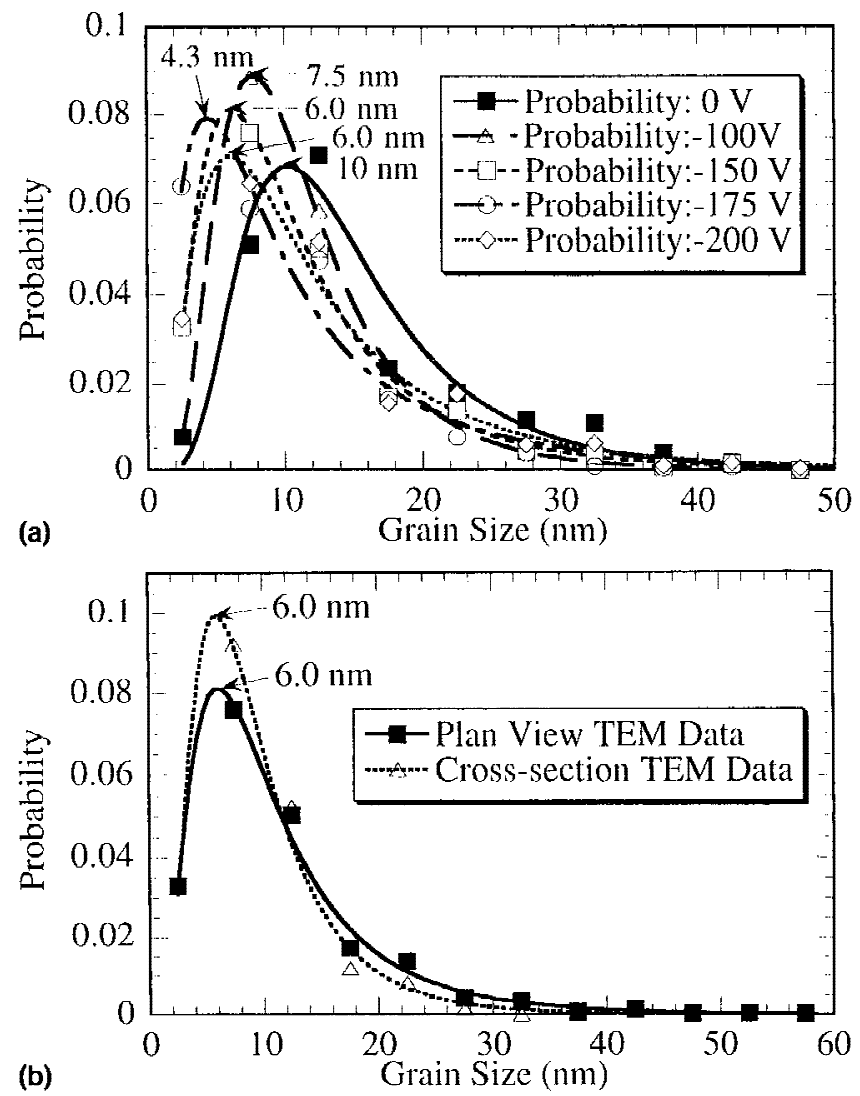

FIG. 10. Grain size distributions of LN Ni films: (a) lognormal plots of size distributions obtained from plan-view TEM studies of films grown using substrate bias of $0,-100,-150,-175$, or $-200 \mathrm{~V}$; (b) comparison of size distributions obtained from plan-view and crosssection TEM studies in LN Ni film grown using $-150 \mathrm{~V}$ substrate bias. 


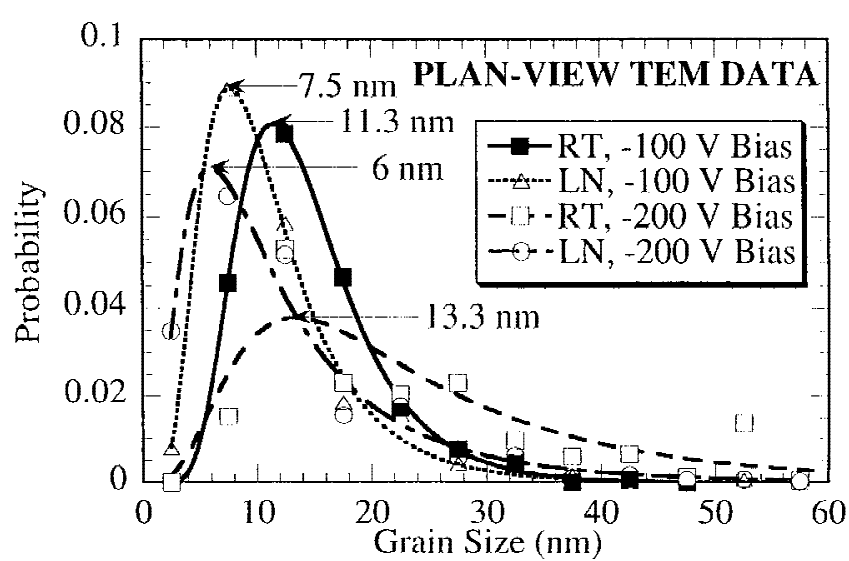

FIG. 11. Comparison between lognormal grain size distributions of RT and LN Ni films grown using cathode power of $200 \mathrm{~W}$ and substrate bias -100 and $-200 \mathrm{~V}$.

Nucleation kinetics is a strong function of the flux of the impinging atoms, deposition temperature, and density of point defects. From the statistical theory of nucleation at a high supersaturation limit for a perfect surface, the nucleation rate $I$ is given by the relation: ${ }^{55}$

$$
I=\mathrm{A} \cdot N^{2} \cdot \exp \left\{\left(2 Q_{\mathrm{des}}-Q_{\mathrm{dif}}\right) / \mathrm{kT}\right\}
$$

where $\mathrm{N}$ is the flux of impinging atoms, $Q_{\mathrm{des}}$ is the desorption energy, $Q_{\text {dif }}$ is the activation energy for surface diffusion, $\mathrm{k}$ is the Boltzmann constant, $T$ is the $\mathrm{ab}$ solute temperature, and $\mathrm{A}$ is a constant dependent on the surface vibrational frequency of adsorbed atoms and a potential barrier. A potential barrier arises from the fact that the binding energy is not uniform over the substrate surface and the adsorbed atoms are thus localized at positions corresponding to the state of minimum energy. Hence, a barrier must be overcome for surface diffusion jump of adsorbed atoms. Equation (4) implies that the nucleation rate increases with a decrease in absolute temperature, since $\left(2 Q_{\mathrm{des}}-Q_{\mathrm{dif}}\right)>0$. If point defects with high binding energy are present on the surface, a single atom adsorbed on such a defect can be considered as the smallest stable cluster or nucleus. The nucleation rate $I_{\mathrm{D}}$ is then given by the relation: ${ }^{55}$

$$
I_{\mathrm{D}}=\mathrm{A} N N_{\mathrm{D}} \cdot \exp \left\{\left(2 Q_{\mathrm{des}}-Q_{\mathrm{dif}}\right) / \mathrm{k} T\right\}
$$

where $N_{\mathrm{D}}$ is the density of point defects on the substrate surface. It is well known that the atoms or clusters of atoms sputtered from the cathodic target possess high energies and retain a considerable part of their energy after reaching the substrate, allowing them to move around even at temperatures in which particles generated by thermal or electron beam evaporation methods would be localized. ${ }^{55}$ These high energy particles also create point defects upon impingement on the substrate leading to the formation of localized dangling bonds with high binding energy, and these act as preferred sites for nu- cleation. This process of defect generation is aided by sputtering of the substrate and the film by positively charged argon ions of the plasma if a negative bias is applied. The critical radius for nucleation decreases with increasing supersaturation and lower substrate temperatures. ${ }^{46}$ Hence use of liquid nitrogen temperature aided by momentum transfer of argon atoms enhances the nucleation rate and site density. It has also been reported $^{19,20,46}$ that nucleation occurs in a narrow vicinity of the impingement site if the substrate temperature is low and the target is a high melting point material, as is the case in the present study. In this condition, due to a high concentration of nucleation centers $\left(10^{15} \mathrm{~cm}^{-2}\right),{ }^{46,55}$ the grain size remains fine and its distribution stays narrow. As the density of nuclei is high, the islands formed on the substrate in the initial stages are very close to one another, which means there exists an attractive interaction between the islands to reduce the potential energy. Thus the film is expected to be almost continuous at early stages of growth. High density is achieved simultaneously because of the high mobility of adatoms maintained by momentum transfer from the high energy sputtering of argon ions when a negative substrate bias is used during deposition.

Contrary to the trend shown by the LN films grown with substrate bias, plan-view TEM studies have shown that the mean grain size $(14 \mathrm{~nm})$ of $0.1-\mu \mathrm{m}$-thick $\mathrm{LN}$ film is marginally larger than that of the RT Ni film $(9 \mathrm{~nm})$. The cross-section micrographs from both RT and LN specimens show columnar grains of similar size, but the RT sample also has a significantly large number fraction of fine equiaxed grains, which the LN film does not have. Thus the growth mechanisms of the RT and LN films are different when no bias is used. There is a possibility that the fine equiaxed grains form in the $0.1-\mu \mathrm{m}$-thick RT films, too, when they are grown on salt substrates, in addition to the columnar grains. The adatom mobility and nucleation pattern could be different on $\mathrm{NaCl}$ substrates than on Si. The equiaxed grains are finer than columnar grains and the number fraction of finer grains is higher (though the larger grains would account for more of vol$u^{6} e^{6}$ ); the mean size obtained from distribution of number fractions of grain sizes would appear smaller in plan-view study. Further research is required to verify the above results.

With an increase in the thickness, grain growth was observed in the LN Ni films with high substrate bias voltage, similar to the observations in case of RT films. Plan-view TEM observation of thicker LN Ni films deposited using a substrate bias of $-100 \mathrm{~V}$ or higher has shown a wide distribution of grain sizes, presumably due to finer grains near the substrate and larger near the film surface [Fig. 12(a)]. Figure 12(b) shows the comparison of lognormal grain size distributions of 0.1 - and 5.0- $\mu \mathrm{m}-$ thick Ni films (from plan-view TEM studies) grown 
using substrate bias voltage of $-100 \mathrm{~V}$, in which the 5.0- $\mu \mathrm{m}$-thick film has much wider grain size distribution. A high concentration of point defects generated by resputtering argon ions enhances grain boundary mobility. From free energy considerations, larger grains would grow at the expense of finer grains. The increase in grain size with increase in thickness is more pronounced at higher substrate temperatures ${ }^{46}$ [also Figs. 5(a) and 5(b)]. The grains tend to possess twin relationships in many cases or have low angle boundaries between them, as was evident from dark-field TEM studies [Fig. 12(a)]; special boundaries in pure metals have lower energy and also lower mobility. It has been $\operatorname{argued}^{56}$ that the relatively "open structure" of high angle boundaries is responsible for higher mobility, whereas denser packing of special boundaries reduces mobility. The $\{111\}$ texture that was found in the diffraction patterns of $0.1-\mu \mathrm{m}$-thick Ni films could not be observed during plan-view TEM studies of the 5.0- $\mu \mathrm{m}$-thick Ni film. However, the $\{111\}$ texture was found in the nanocrystalline region [as in Fig. 9(b)]

(a)
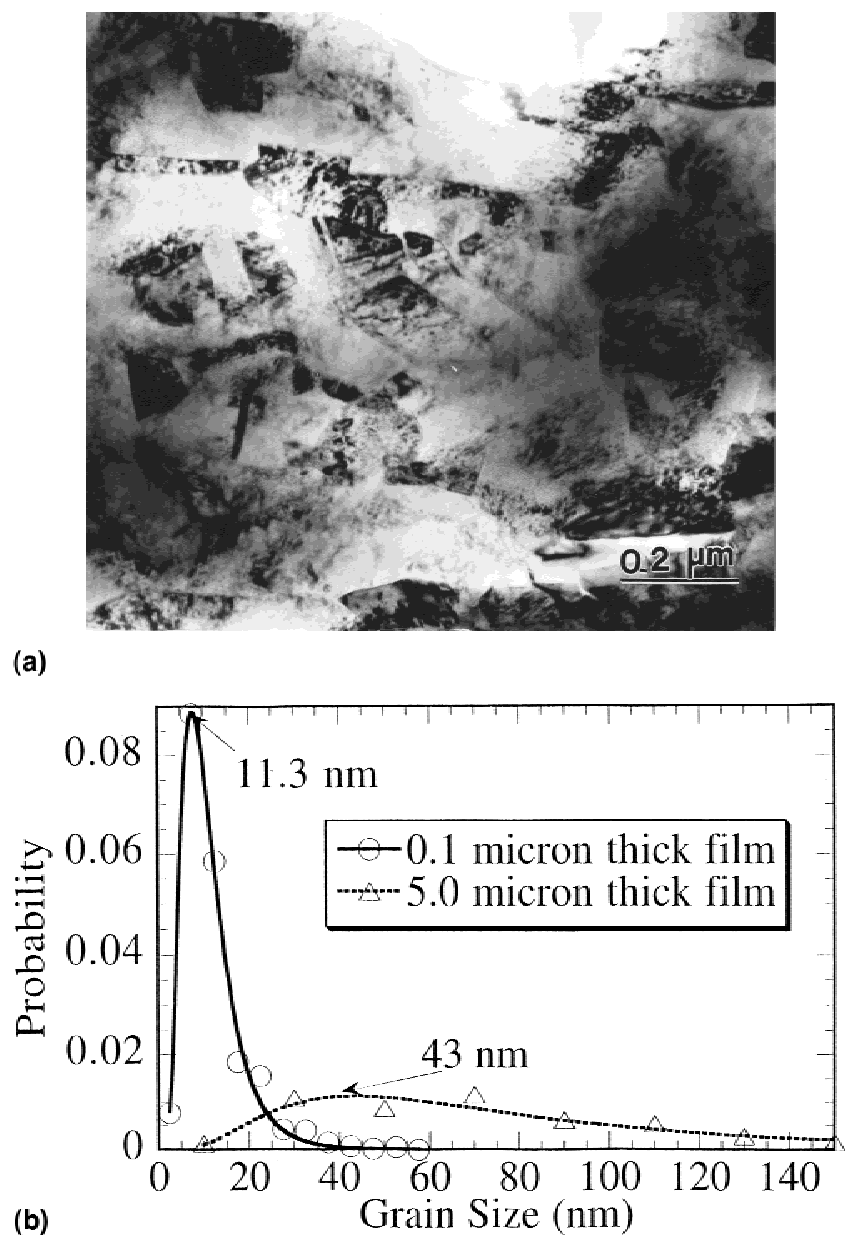

FIG. 12. (a) Bright-field plan-view TEM image of 5.0- $\mu$ m-thick Ni film; (b) comparison of the lognormal plots of grain size distributions of 0.1 - and 5.0- $\mu \mathrm{m}$-thick LN Ni films, the grain sizes being measured from plan-view TEM images. of cross-section TEM specimens. The texture apparently disappears during secondary recrystallization and subsequent grain growth.

\section{Surface topography and pore distribution}

In general, comparison of the surfaces of LN Ni films with those of RT Ni films has shown that that latter are less porous, and this observation can be explained by the higher atomic mobility in the film at higher temperature. The problem of sticking of neutral argon atoms reflected from the target to the film would be more severe when cooled using liquid nitrogen during growth, as compared to that grown at room temperature. While warming up, the entrapped gas would escape, leaving behind the pores.

Figures 13(a) and 13(b) are optical images of the surface of 2.0- $\mu \mathrm{m}$-thick $\mathrm{Ni}$ films grown at liquid nitrogen temperature, using bias voltages of 0 and $-150 \mathrm{~V}$

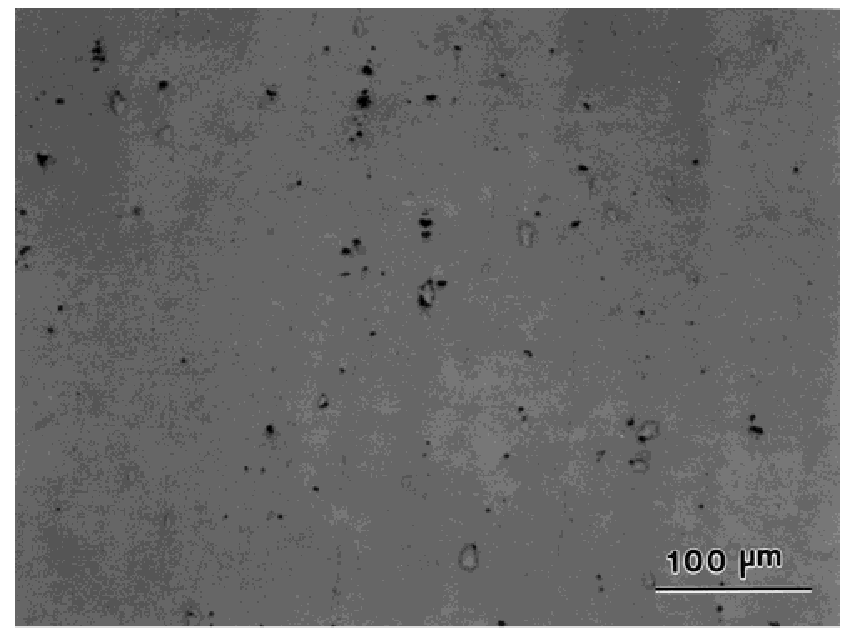

(a)

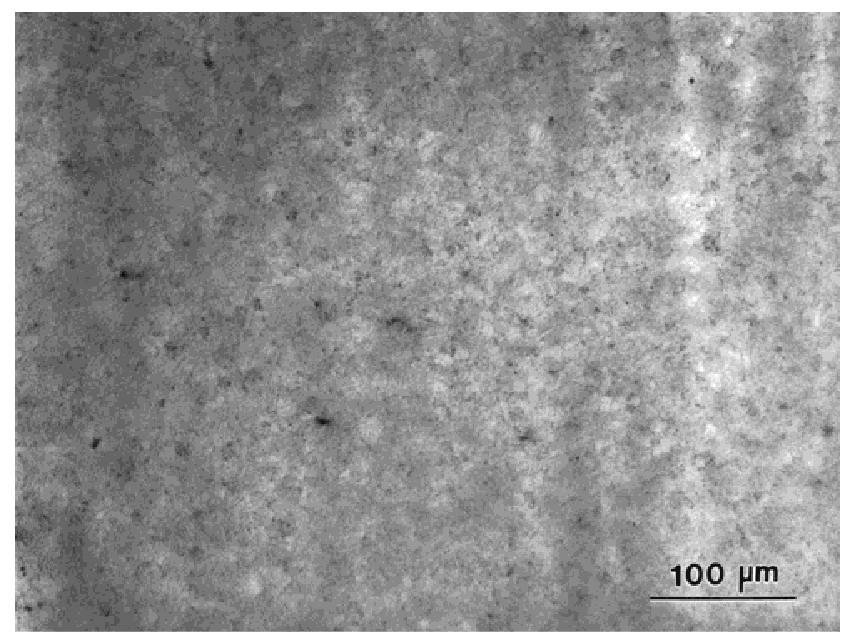

(b)

FIG. 13. Optical micrographs of the surface of 2.0- $\mu$ m-thick LN Ni films grown using a cathode power of $200 \mathrm{~W}$ and substrate bias of (a) $0 \mathrm{~V}$ and (b) $-150 \mathrm{~V}$. 
respectively. It is quite obvious that the surface of the film grown at $0 \mathrm{~V}$ bias is very porous [Fig. 13(a)], and the pores are large in size. The films grown at $-150 \mathrm{~V}$ bias [Fig. 13(b)] show fewer pores as compared to the films grown at $0 \mathrm{~V}$ bias. Also the thin films grown at bias of -100 or $-150 \mathrm{~V}$ [Fig. 13(b)] are smooth as compared to the film grown at $0 \mathrm{~V}$ bias. The roughness of the film increased on increasing the bias above $-150 \mathrm{~V}$, similar to the observations on RT Ni films. Figures 14(a) and 14(b) show the surface relief of thicker nickel films $(6-8 \mu \mathrm{m}$ thick). The surface of the 7.5- $\mu \mathrm{m}$-thick Ni film, grown with $0 \mathrm{~V}$ substrate bias [Fig. 14(a)] is porous like the $2.0-\mu \mathrm{m}$-film [Fig. 13(a)] and even rougher. Increase in surface roughness with increase in thickness of the films has been reported in the past. ${ }^{57,58}$ Under the conditions of low atomic mobility on the substrate, the surface roughness parameter of the film $\Delta t$, defined as the average deviation from the mean film thickness $t$, is statistical in

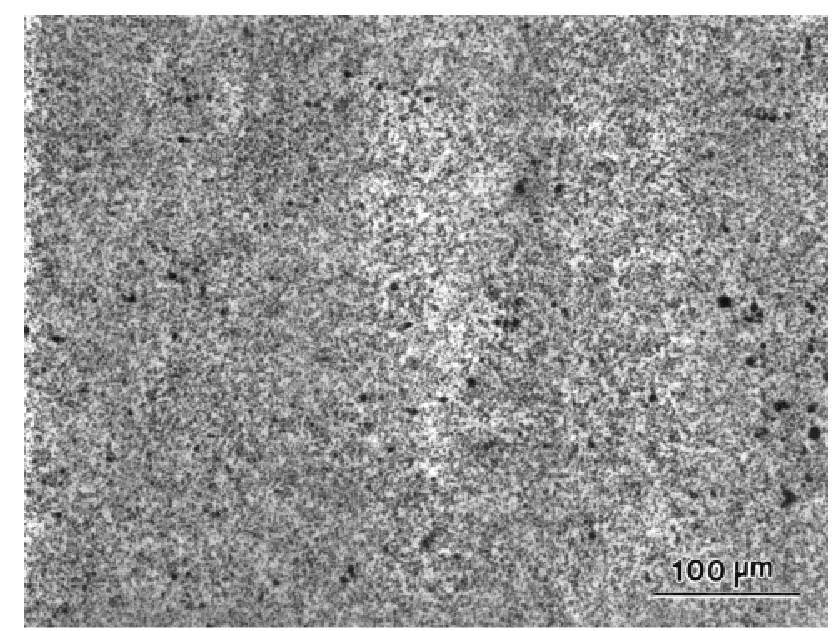

(a)

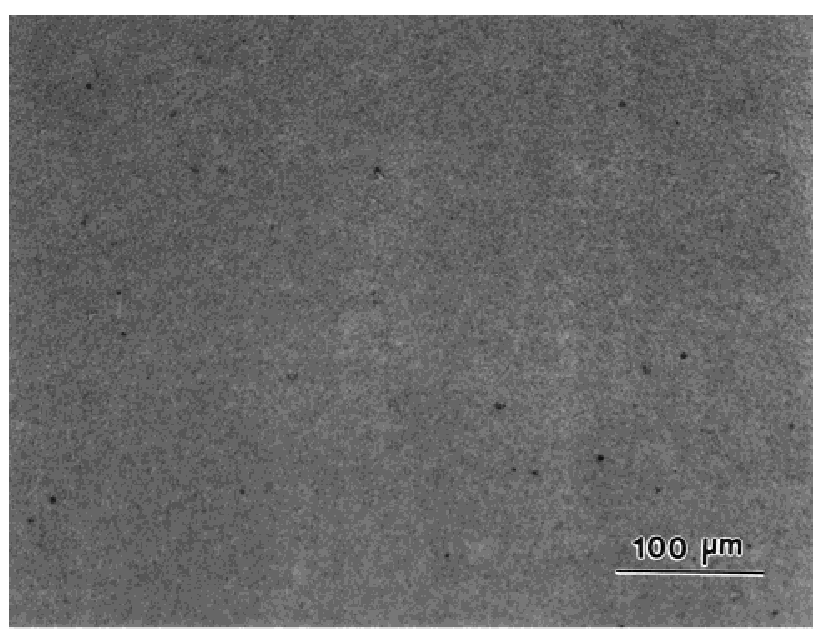

(b)

FIG. 14. Optical micrographs of 6-8- $\mu$ m-thick LN Ni film grown using a cathode power of $200 \mathrm{~W}$ and substrate bias of (a) $0 \mathrm{~V}$ and (b) $-150 \mathrm{~V}$. nature and is expressed by a Poisson distribution, which implies $^{46} \Delta t \propto t^{1 / 2}$. In the case of $0 \mathrm{~V}$ substrate bias condition at liquid nitrogen temperature, the atomic mobility on the substrate is low and the growth is columnar. This explains the high roughness at higher thickness. Both the roughness and the porosity decreased as a substrate bias of -100 or $-150 \mathrm{~V}$ was applied [Fig.14(b)]. The resputtering by argon ions increases the atomic mobility on the surface. As surface atomic mobility is increased, the concavities are filled up, and the surface of the film becomes smooth. However, roughness was high in the case of the thick film made using $-200 \mathrm{~V}$ bias; the reason for which is discussed in Sec. III. A. 2. on surface topography and pore distribution of RT films.

\section{Residual stress measurements}

The residual stresses in the Ni film vary with the substrate bias and temperature of deposition, as in Fig. 15. The large residual stress is tensile in the films grown under different conditions and the trend differed based on the temperature of deposition. Among the RT Ni films, the maximum stress of about $1.0 \mathrm{GPa}$ was found in the film grown at a bias of $-100 \mathrm{~V}$. In the case of $\mathrm{LN} \mathrm{Ni}$ films, the maximum residual stress of $1.04 \mathrm{GPa}$ was measured in the film grown without any bias, and a fall in stress was noticed with an increase in the substrate bias. Young's modulus and Poisson's ratio of bulk nickel are $207 \mathrm{GPa}$ and 0.31 , respectively, implying that the biaxial modulus is $300 \mathrm{GPa}$. The modulus of Ni films grown at $0 \mathrm{~V}$ bias would be lower than that of bulk sample due to porosities. The residual strain in the films calculated from the above data varies between 0.0014 and 0.003 . The values of residual strains in the nanocrystalline Ni thin films of this study are similar to what has been observed in nanocrystalline $\mathrm{Cu}, \mathrm{Pd}$, and $\mathrm{Ni}$ samples processed by inert gas condensation. ${ }^{3,59}$ Measurements

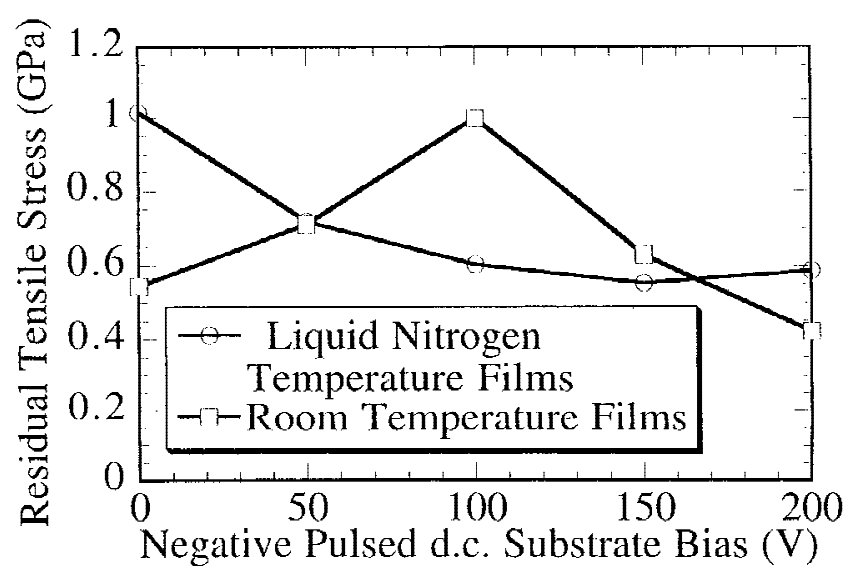

FIG. 15. Variation of the magnitude of the tensile residual stress in the RT and LN Ni films with substrate bias. 
of residual stress in 1.0- and 2.0- $\mu$ m-thick RT films grown at $-100 \mathrm{~V}$ bias showed that the magnitude of stress was the same in either situation.

The variation of residual stress in the RT Ni films with increase in the substrate bias is qualitatively similar to the observations of Misra and Nastasi ${ }^{15,38}$ in their study of residual stress evolution in the room-temperaturedeposited $\mathrm{Cr}$ films. The residual tensile stress in $\mathrm{Cr}$ films was found to reach a peak at $-50 \mathrm{~V}$ bias followed by a decrease. The tensile stress maximum has been attributed to the maximum in attractive interatomic forces between coalescing islands or crystallites ${ }^{29,38,60,61}$ (thin, noncontinuous films) and/or constrained grain boundary relaxa$\operatorname{tion}^{29,62}$ (thin, continuous films). The boundaries of islands are attracted to one another but are constrained by their adhesion to the substrate. On increasing the rate of ion bombardment of the film with application of substrate bias, the adatom mobility is enhanced and the islands form close to one another. When the islands are closer and tend to coalesce (island coalescence), the magnitude of attractive interatomic forces increases, and the tensile residual stress also increases.

As the pores are located at grain boundaries in a thin continuous film, the interatomic distance at grain boundaries is larger than the equilibrium distance. With the reduction in the sizes of pores mostly located at and near the grain boundaries in the film, the atoms near the grain boundary are relaxed to a more equilibrium position in which the packing density near grain boundaries is increased (grain boundary relaxation). For the grain boundary voids to shrink, atoms have to flow from the boundary to the void, and this involves rigid body motion of two grains toward each other, so as to maintain contact between them. As a result of the constraint due to adhesion with substrate, the gap created by displacement of atoms at grain boundary is closed only by elastic straining within the grains. At a grain size of $50 \mathrm{~nm}$ in $\mathrm{Ni}$ and void fraction of $3 \times 10^{-3}$, the residual stress developed on shrinking of the voids to atomic size has been found to be $1.1 \mathrm{GPa},{ }^{29}$ which is close to the maximum stress measured in the present study.

Thus the magnitude of the tensile residual stress increases as the bias is increased from $0 \mathrm{~V}$ to $-100 \mathrm{~V}$. However, the tensile residual stress in films decreases as islands come closer or merge, which is expected with an increase in the adatom mobility, occurring with an increase in the temperature of deposition ${ }^{28,61}$ or with an increase in the substrate bias. The stress becomes more compressive with introduction of Frenkel pairs and loops formed by self-interstitials and entrapment of argon atoms, ${ }^{39}$ which is minimum at a bias of $-100 \mathrm{~V}$ and is higher at zero bias or if higher negative bias is used. ${ }^{52}$

At liquid nitrogen temperature of deposition, the nucleation density of islands is higher as the critical radius is smaller as discussed above Sec. III. B. 1. The average spacing between the islands is possibly small enough at zero-bias conditions for the maximization of interatomic forces and hence the highest tensile residual stress. As the adatom mobility increases with increase in the substrate bias, rearrangement of atoms arriving at the surface of the film is faster, and the islands come closer and merge leading to lowering of interatomic forces, which in turn lowers the tensile residual stress.

\section{Nanoindenter hardness of Ni films}

Table III shows the hardness of the nanocrystalline nickel films of thickness in the ranges of $1.5-2.5 \mu \mathrm{m}$ (thin) and 6-8 $\mu \mathrm{m}$ (thick), processed using $200 \mathrm{~W}$ target power in this study. Each hardness reading is an average of data obtained from 15 to 20 indentations. The hardness values also match those observed in bulk nanocrystalline $\mathrm{Ni}$ samples processed by $\mathrm{IGC}^{3}$ and electroplating (EP) methods. ${ }^{8}$ The mean grain sizes of the films used for hardness measurements are expected to be somewhat larger than that found in the $0.1-\mu \mathrm{m}$-thick film, which was explained earlier in this paper with illustrations

TABLE III. Hardness of thin and thick films of Ni grown on steel substrates at room and liquid nitrogen temperatures. Hardness data of nanocrystalline Ni processed by inert gas condensation ${ }^{3}$ and electroplating ${ }^{8}$ and annealed coarse-grained Ni are shown for comparison.

\begin{tabular}{|c|c|c|c|}
\hline Temperature & $\operatorname{Bias}(\mathrm{V})$ & $\begin{array}{l}\text { Hardness (GPa) of } \\
1.5-2.5-\mu \mathrm{m} \text {-thick film }\end{array}$ & $\begin{array}{l}\text { Hardness (GPa) of } \\
6-8-\mu \mathrm{m} \text {-thick film }\end{array}$ \\
\hline room & 0 & $5.5 \pm 0.2$ & \\
\hline room & -100 & $4.7 \pm 0.2$ & $3.8 \pm 0.1$ \\
\hline room & -150 & $4.6 \pm 0.2$ & $3.7 \pm 0.1$ \\
\hline room & -200 & $6.7 \pm 0.3$ & \\
\hline liquid nitrogen & 0 & $6.3 \pm 0.3$ & $5.4 \pm 0.2$ \\
\hline liquid nitrogen & -100 & $6.2 \pm 0.3$ & $3.3 \pm 0.1$ \\
\hline liquid nitrogen & -150 & $5.4 \pm 0.2$ & $3.8 \pm 0.1$ \\
\hline liquid nitrogen & -200 & $6.6 \pm 0.3$ & $5.1 \pm 0.2$ \\
\hline Ni-IGC, $97.2 \%$ dense & & & \\
\hline Electroplated Ni & & & \\
\hline Annealed coarse grained $\mathrm{Ni}$ & & & \\
\hline
\end{tabular}


[Figs. 5(a), 5(b), 12(a), and 12(b)]. However, similar trend as observed in the $0.1-\mu \mathrm{m}$-thick films is expected in the thicker films with changes in substrate bias or temperature during deposition.

The higher hardness of films processed at liquid nitrogen temperature is clearly evident. This trend probably is due to the smaller mean grain size and narrow grain size distributions in the films grown at liquid nitrogen temperature. Supersaturation of point defects could also lead to higher hardness in $1.5-2.5-\mu \mathrm{m}$-thick $\mathrm{LN}$ films, as compared to RT films of similar thickness grown with application of substrate bias. The hardness of the Ni film deposited using $-200 \mathrm{~V}$ substrate bias is high, whether the substrate is held at room temperature or cooled by flowing liquid nitrogen. This is probably due to the high density of point defects, both vacancies and selfinterstitials and their clusters, introduced in the film by excessive resputtering. Self-interstitials possess a dialational strain field, ${ }^{63,64}$ while vacancies have a compressive strain field and contribute to hardening as both of these pin the dislocations. ${ }^{63}$

The RT and LN Ni films grown at $0 \mathrm{~V}$ bias and possessing columnar grain structure have high hardness too, which is in agreement with observations reported by Thornton. ${ }^{31}$ These would, however, lead to poor strength in the transverse direction. It is also observed that $\mathrm{LN} \mathrm{Ni}$ film grown without bias has higher hardness than the corresponding RT Ni film, inspite of having marginally higher grain size. Probably a higher than equilibrium concentration of vacancies trapped in the LN Ni film during deposition is responsible for high hardness. High residual stress (Fig.15) in the LN film grown with no bias may have also contributed to the high hardness observed.

The hardness values of RT Ni films grown at -100 and $-150 \mathrm{~V}$ bias are lower than that grown without bias due to increase in the grain size with increase in bias in the RT films. This decrease in hardness is noticed inspite of the fact that the density improves and grain morphology is equiaxed. The hardness of the films tends to decrease with an increase in the thickness of the films. An increase in the average grain size with increase in thickness of the film has been observed in the present study [Figs. 5(a), 5(b), and 12(b)], which is one possible reason for a decrease in the hardness. Another reason could be the loss of $\langle 111\rangle$ texture with increase in thickness, and when bias is increased, which is again more pronounced in the RT films. RT Ni film of 1.5- $\mu$ m thickness has shown a tendency towards $\langle 100\rangle$ texture, while $\mathrm{LN} \mathrm{Ni}$ film of similar thickness has shown very strong <111> texture. Ni single crystals have large elastic anisotropy, ${ }^{65}$ $E_{111}=300 \mathrm{GPa}$ and $E_{100}=136 \mathrm{GPa}$. Hence <111> fiber texture is likely to increase the hardness of the film, and loss of texture would reduce the hardness. The change in the residual elastic strain with thickness can be another possibility. However, Klokholm and Berry, ${ }^{66}$ us- ing a cantilever method, observed that elastic strain was almost unchanged with increase in thickness of Ni film on a glass substrate in the range of 0.2 to $1.0 \mu \mathrm{m}$. In the present study, the magnitude of stress was the same for the RT film thickness of 1.0 and $2.0 \mu \mathrm{m}$, as has been reported in the earlier section. But there could be a decrease with further increase in thickness due to changes in grain size because the larger grains can undergo plastic deformation to relax the elastic strain.

\section{CONCLUSIONS}

A thorough study has been undertaken on the grain structure and size distribution, surface morphology, residual stress and hardness of nanocrystalline nickel films of different thickness grown by magnetron sputtering at room and liquid nitrogen temperatures using substrate bias between 0 and $-200 \mathrm{~V}$. The following conclusions are drawn on the basis of the present investigation.

(1) The grain size distributions follow a lognormal relationship. While the grain sizes remain nanocrystalline in all cases, the grain size distribution (plan-view) in the RT films widen with increase of substrate bias voltage from 0 to $-200 \mathrm{~V}$, while using a sputtering source power of $200 \mathrm{~W}$. This has been explained on the basis of substrate heating and higher diffusivity. On the other hand, the mean grain sizes in the LN films remain independent of the substrate bias voltage, with the mode of the distribution decreasing with increasing substrate bias voltage.

(2) The grains of Ni films grown at room and liquid nitrogen temperatures were equiaxed when a substrate bias voltage was applied. The grains tend to have a columnar morphology in the RT as well as LN films grown without a bias voltage. Equiaxed grains nucleate on the facets of columnar grains in the RT Ni film grown without bias, with progress of deposition.

(3) TEM studies of plan-view and cross-section specimens suggest that the average grain size increases with increase in the thickness of the film due to secondary recrystallization and subsequent grain growth.

(4) Study of cross-section TEM specimens has shown that an increase in the power of the sputtering source from 200 to $400 \mathrm{~W}$, while keeping the substrate bias voltage at $-100 \mathrm{~V}$, leads to the formation of columnar grain-structure. This suggests that it is necessary to increase the bias voltage proportionally in response to the higher deposition rate obtained on increasing the sputtering source power.

(5) Qualitative optical examination of the surfaces of the Ni films has shown that the RT films contain less porosity than the LN films, probably as a result of the higher mobility of adsorbed atoms during room temperature deposition and less argon entrapment. In the LN films, the number of pores per unit area and pore size 
decrease with increase in the substrate bias voltage. The surface roughness of RT and LN Ni films is high when the substrate bias voltage is $-200 \mathrm{~V}$ due to damage caused by high dose of ion bombardment, leading to formation of clusters of point defects and steps. The LN Ni film surface roughness also increases with an increase in thickness of the films grown at $0 \mathrm{~V}$ or $-200 \mathrm{~V}$ substrate bias voltages. The surfaces of the thick LN films grown at intermediate bias voltages are relatively smooth.

(6) Tensile residual stress has been found in the RT and LN Ni films deposited on Si substrates. The variation of magnitude of the stress with substrate bias is different at room and liquid nitrogen temperatures of deposition. While the stress maximum of $1 \mathrm{GPa}$ has been observed in the film grown with $-100 \mathrm{~V}$ bias at room temperature, the same maximum has also been measured in the film grown without bias at liquid nitrogen temperature. The stress is less in the RT Ni films grown with bias more or less than $-100 \mathrm{~V}$. In the LN Ni films, stress decreases with increase in the substrate bias voltage and does not show much change beyond $-100 \mathrm{~V}$ bias.

(7) The hardness values of nanocrystalline Ni films are similar to those of bulk nanocrystalline specimens of similar grain sizes grown by inert gas condensation or electroplating techniques. The hardness values are much higher than those of microcrystalline or coarse-grained nickel samples. The mean hardness of the LN Ni films is higher than that of RT Ni films, probably due to finer grain sizes, narrower grain size distribution, and possibly also due to stronger $\langle 111\rangle$ texture and superstaturation of point defects in the former. Hardness also decreases with increase in thickness due to increase in grain size as well as loss of $<111>$ texture.

\section{ACKNOWLEDGMENTS}

Financial support from the United States Department of Energy, office of Basic Energy Science- Materials Science, under Grant No. DE-FGO2-86ER45229 at Northwestern University. This research also made use of the Materials Research Center Facilities at Northwestern University, supported by the National Science Foundation under Grant No. DMR-9632742. One of the authors (R.M.) is grateful to Defence Research and Development Organization, New Delhi, India for leave of absence to pursue this research.

\section{REFERENCES}

1. P.G. Sanders, J.A. Eastman, and J.R. Weertman, Acta Mater. 45, 4019 (1997).

2. J.R. Weertman, D. Farkas, K. Hemker, H. Kung, M. Mayo, R. Mitra, and H. VanSwygenhoven, MRS Bull. 24(2), 44 (1999).

3. B.R. Elliot, Ph.D. Dissertation, Northwestern University, Evanston, IL (December 1998).
4. M. Zupan, M. Legros, B.R. Elliott, and K.J. Hernker, in Advanced Materials for the 21st Century: The JuliaR. Weertman Symposium, edited Y-W. Chung, D.C. Dunand, P.K. Liaw, and G.B. Olson (TMS, Warrendale, PA, 1999), p. 525.

5. R. Birringer, H. Gleiter, H-P. Klein, and P. Marquardt, Phys. Lett. 102A, 365 (1984).

6. R. Mitra, T. Ungar, T. Morita, P.G. Sanders, and J.R. Weertman, in Advanced Materials for the 21st Century: The 1999 Julia R. Weertman Symposium, edited by Y-W. Chung, D.C. Dunand, P.K. Liaw, and G.B. Olson (TMS, Warrendale, PA, 1999), p. 553.

7. S.R. Agnew, B.R. Elliott, C.J. Youngdahl, K.J. Hemker, and J.R. Weertman, in Modeling of Structure and Mechanics of Materials from Microscale to Product, edited by. J.V. Carstensen, T. Leffers, T. Lorentzen, O.B. Pedersen, B.F. Sørensen, and G. Winther (Ris $\varnothing$ National Laboratory, Roskilde, Denmark, 1998), p. 1.

8. A.M. EI-Sherik, U. Erb, G. Palumbo, and K.T. Aust, Scripta Metall. Mater. 27, 1185 (1992).

9. F. Ebrahimi, G.R. Bourne, M.S. Kelly, and T.E. Matthews, Nanostruct. Mater. 11, 343 (1999).

10. K.T. Aust, Can. Metall. Quart. 34, 165 (1994).

11. D.G. Morris and M.A. Morris, Acta Metall. Mater. 39, 1763 (1991).

12. H. Hahn and R.S. Averback, J. Appl. Phys. 67, 1113 (1990).

13. G.M. Chow and A.S. Edelstein, Nanostr. Mater. 1, 107 (1992).

14. J.B. Savader, M.R. Scanlon, R.C. Carnrnarata, D.T. Smith, and C. Heyzelden, Scripta Metall. 36, 29 (1997).

15. A. Misra and M. Nastasi, J. Mater. Res. 14, 4466 (1999).

16. J. Musil and F. Regent, J. Vac. Sci. Technol. A 16, 3301 (1998).

17. M.N. Rittner, J.A. Eastman, and J.R. Weertman, Scripta Metall. Mater. 31, 841 (1994).

18. F.A. Doljack and R.W. Hoffman, Thin Solid Films 12, 71 (1972).

19. H.T.G. Hentzell, B. Anderson, and S-E. Karlsson, Acta Metall. 31, 2103 (1983).

20. C.R.M. Grovenor, H.T.G. Hentzell, and D.A. Smith, Acta Metall. 32, 773 (1984).

21. S.D. Dahlgren, W.L. Nicholson, M.D. Merz, W. Bollmann, J.F. Devlin, and R. Wang, Thin Solid Films 40, 345 (1977).

22. D.M. Mattox and G.J. Kominiak, J. Vac. Sci. Technol. 9, 528 (1972).

23. R.D. Bland, G.J. Kominiak, and D.M. Mattox, J. Vac. Sci. Tech. 11, 671 (1974).

24. R.F. Bunshah, Vacuum 20, 353 (1977).

25. K.N. Tu, in Treatise on Materials Science and Technology, Vol. 24: Preparation and Properties of Thin Films, edited by. K.N. Tu and R. Rosenberg (Academic Press, New York, 1982), p. 237.

26. L.I. Maissel, in Handbook of Thin Film Technology, edited by L.I. Maissel and R. Glang, (McGraw Hill, New York, 1983), p. 1.

27. E.S. Machlin, Materials Science in Microelectronics: The relationships between thin film processing and structure (Giro Press, Carton-on-Hudson, NY, 1995) p. 157.

28. R. Abermann, Vacuum 41, 1279 (1990).

29. M.F. Doerner and W.D. Nix, CRC Crit. Rev. Solid State Mater. Sci. 14, 225 (1988).

30. B.A. Movchan and A.V. Demshishin, Fiz. Met. Metalloved. 28, 653 (1969).

31. J.A. Thornton, J. Vac. Sci. Techol. 11, 666 (1974).

32. G.G. Stoney, Proc. Roy. Soc. London A82, 172 (1909).

33. P.L. Gai, E.I. Du Pont De Nemours and Company (Inc.), Wilmington, DE (private communication).

34. R.A. Schwarzer, in Trends and New Applications of Thin Films, edited by H. Hoffman (Trans Tech, Uetikon-Zuerich, Switzerland., 1998); Mater. Sci. Forum 287-288, 38 (1998).

35. C.C. Wong, H.I. Smith, and C.V. Thompson, Appl. Phys. Lett. 48, 335 (1986). 
36. Powder Diffraction File, Card No. 4-850 Inorganic Phases, JCPDS International Centre for Diffraction Data, (Swarthmore, PA, 1989).

37. J.A. Thornton, Ann. Rev. Mater. Sci. 7, 239 (1977).

38. A. Misra and M. Nastasi, Appl. Phys. Lett. 75, 3123 (1999).

39. E.M. Zielinski, R.P. Vinci, and J.C. Bravman, J. Appl. Phys. 76, 4516 (1994).

40. C.V. Thompson, Ann. Rev. Mater. Sci. 20, 245 (1990).

41. E.B. Haugen, Probabilistic Approaches to Design (John Wiley and Sons, New York, 1968), p.47.

42. A. Misra, S. Fayeulle, H. Kung, T.E. Mitchell, and M. Nastasi, Appl. Phys. Lett., 73, 891 (1998).

43. J.A. Thornton, J. Vac. Sci. Tech. A 4, 3059 (1986).

44. M.Y. Fuks, L.S. Palatnik, A.A. Koz'ma, A.A. Nechitaylo, and O.N. Grigor'yev, Fiz. Metal. Metalloved. 28, 645 (1969).

45. R. Mitra, W.A. Chiou, J.R. Weertman, and R. Hoffman, in Proc. Microscopy and Microanalysis, edited by G.W. Bailey, W.G. Jerome, S. McKernan, J.F. Mansfield and R.L. Price (Springer Verlag, NY, 1999), Vol. 5, Suppl. 2, p. 834.

46. K.L. Chopra, Thin Film Phenomena (McGraw-Hill, New York, 1969), p. 137.

47. P. Wang, D.A. Thompson, and W.W. Smeltzer, Nucl. Inst. Meth. Phy. Res. 87/8, 97 (1985).

48. P. Wang, D.A. Thompson, and W.W. Smeltzer, Nucl. Inst. Meth. Phy. Res. B16, 288 (1986).

49. H.A. Atwater, C.V. Thompson,, and H.I. Smith, J. Appl. Phys. 62, 2337 (1988).

50. J.C. Liu, J. Li, and J.W. Mayer, in Processing and Characterization of Materials Using Ion Beams, edited by L.E. Rehn, J. Greene, and F.A. Smidt (Mater. Res. Soc. Symp. Proc. 128, Pittsburgh, PA, 1989), pp. 297-302.
51. J.A. Thornton, Thin Solid Films 40, 335 (1977).

52. H.F. Winters and E. Kay, J. Appl. Phys. 38, 3928 (1967).

53. B.J. Garrison and N. Winograd, J. Vac. Sci. Tech. 16, 789 (1979).

54. K.C. Thompson-Russell and J.W. Edington, Electron Microscope Specimen Preparation Techniques in Materials Science, Philips Technical Laboratory Monographs in Practical Electron Microscopy in Materials Science [(N.V. Philips') Gloeilampenfabrieken, Eindhoven, The Netherlands, 1977], Vol. 5, pp. 13,14.

55. L. Eckertova, Physics of Thin Films (Plenum Press, New York, 1986), Chap. 4, p. 96.

56. D.A. Porter and K.E. Easterling, Phase Transformations in Metals and Alloys (Chapman and Hall, London, United Kingdom, 1991), Chap. 3, p. 110.

57. O. Beeck, Advan. Catalysis 2, 151 (1950).

58. D. Brennan, D.O. Hayward, and B.M.W. Trapnell, Proc. Roy. Soc. London A256, 81 (1960).

59. P.G. Sanders, Ph.D. Dissertation, Northwestern University, Evanston, IL (1996).

60. A.L. Shull and F. Spaepen, J. Appl. Phys. 80, 6243 (1996).

61. W.D. Nix and B.M. Clemens, J. Mater. Res. 14, 3467 (1999).

62. R.W. Hoffman, Thin Solid Films 34, 185 (1976).

63. J. Weertman and J.R. Weertman, Elementary Dislocation Theory, Macmillan Series in Materials Science (Collier-Macmillan, Toronto, Canada,1964), Chap. 6, p. 168.

64. R.L. Fleischer, in The Strengthening of Metals, edited by D. Peckner (Reinhold Press, New York, 1964), p. 93.

65. R.W. Hertzberg, Deformation and Fracture Mechanics of Engineering Materials (John Wiley and Sons, New York, 1989), Chap. 1, p.3.

66. E. Klokholm and B.S. Berry, J. Electrochem. Soc. 115, 823 (1968). 